\title{
Performance-based ECCS cladding acceptance criteria: a new simulation approach
}

\author{
A. Zoino ${ }^{\mathrm{a}}$, A. Alfonsi ${ }^{\mathrm{b}}$, C. Rabiti ${ }^{\mathrm{b}}$, F. Giannetti ${ }^{\mathrm{a}}$, G. Caruso ${ }^{\mathrm{a}}$ \\ ${ }^{a}$ Sapienza, University of Rome, Department of Astronautical, Electrical and Energy Engineering, \\ Nuclear Section - C.so Vittorio Emanuele II, 244 - 00186 Rome, Italy \\ ${ }^{b}$ Idaho National Laboratory, 2525 Fremont Avenue, Idaho Falls, ID 83415 \\ angelo@zoino.it, andrea.alfonsi@inl.gov,cristian.rabiti@inl.gov,fabio.giannetti@uniromal.it, \\ gianfranco.caruso@uniromal.it
}

\begin{abstract}
The U. S. Nuclear Regulatory Commission is currently proposing rulemaking to revise the Loss Of Coolant Accident (LOCA) and therefore the Emergency Core Cooling System (ECCS) acceptance criteria, to include the effects of higher burnup on cladding performance as well as to address other technical issues. As motivated by the new rule, the need to use advanced cladding designs may be a result. A loss of operational margin may result due to the more restrictive cladding embrittlement criteria. Initial and future compliance with the rule may significantly increase vendor workload and licensee cost, as a spectrum of fuel rod initial burnup states may need to be analyzed to demonstrate compliance. Consequently, there will be an increased focus on licensee decision making related to LOCA analysis to minimize cost and impact, and to manage margin.

The study here presented has been part of a big project used to investigate technical issues and approaches for future industrial applications within the Risk-Informed Safety Margin Characterization (RISMC) Pathway. Specifically, the primary aim of this study is to lay out a roadmap to demonstrate the application of the new methodology. The present analysis shows a simplified version of the methodology of an industrial application on the Core Design and the Multi-Cycle Analysis.
\end{abstract}




\section{Introduction}

The ECCS cooling performance is calculated in accordance with an acceptable evaluation model that calculates evolution and effects of different types of Loss Of Coolant Accidents (LOCA). According to the rule 10 CFR 50.46 (U.S. Code of Federal Regulations, 1997) that defines the acceptance criteria for emergency core cooling systems for light-water nuclear power reactors:

[...] ECCS cooling performance must be calculated in accordance with an acceptable evaluation model and must be calculated for a number of postulated Loss Of Coolant Accidents of different sizes, locations, and other properties sufficient to provide assurance that the most severe postulated Loss Of Coolant accidents are calculated. [...]

Two methods are allowed to conduct the analysis in compliance with the rule. A conservative method shown in Appendix $\mathrm{K}$ part 50 and the acceptable features for the ECCS Performance Evaluation Models (EMs).

Otherwise [...] the evaluation model must include sufficient supporting justification to show that the analytical technique realistically describes the behavior of the reactor system during a Loss Of Coolant Accident. Comparisons to applicable experimental data must be made and uncertainties in the analysis method and inputs must be identified and assessed so that the uncertainty in the calculated results can be estimated. This uncertainty must be accounted for, so that, when the calculated ECCS cooling performance is compared to the criteria set forth in paragraph (b) of this section, there is a high level of probability that the criteria would not be exceeded. [...]

The methods are built to have a reasonable gap from the risk. Specific "design-basis" accidents serve as proxies for a certain portion of the spectrum of challenges to plant safety functions; satisfactory performance in these types of accidents (based on conservative analysis) is considered to be evidence of a certain kind of "safety." The limiting case and an appropriate margin to acceptance criteria give the performance of the safety systems. Classically, the identification of the limiting case was done manually, leading to numerous instances in which the analysis of record was based on a non-limiting case.

The Best Estimate Plus Uncertainties (BEPU) method is one of them. In order to satisfy the US Nuclear Regulatory Commission (NRC) expectations, the BEPU method is regulated by Regulatory Guides 1.157 (U.S. NRC, 1989) and 1.203 (U.S. NRC, 2005). As already mentioned, BEPU method 
today has an high degree of conservativism, to cover lacks of knowledge in some phenomena and to ease licensing and implementation. It is today used by the most important industries in the field.

Theoretically, the best method should be to predict the real state of the plant and all the correlated uncertainties. But the "nominal" state of the device (given plant, scenario, etc.) and the "true/theoretical value of total uncertainty" are usually unavailable.

In practice, our knowledge isn't perfect and conservativism must be added to enable the execution and licensing of the analysis. Penalizations are added and also additional margin with the Wilks' method (Wilks, 1941) are added after the estimation of the total uncertainty. This method is currently used for a large number of the Pressurized Water Reactor (PWR) fleet in the United States.

On the other hand, with the development of new cladding materials, the industries have increased the fuel utilization and, consequently, the burnup of the fuel. The discharge burnup has almost doubled in the last two decades. As the industries, also NRC is moving forward, studying the fuel degradation effects under extended irradiation and updating rules. Oxidation, embrittlement and deformation of fuel and deformation of fuel cladding under LOCA conditions have been extensively investigated (Parsons et al., 1986; Leistikow and Schanz, 1987). The current regulatory limit for the burnup is 62 $\mathrm{MWd} / \mathrm{kg}$, however the limit is still likely to be increased moving forward.

Tests in and out of the reactor have been performed and data have been collected to improve knowledge on cladding creep, diffusion constants for $\alpha$ to $\alpha+\beta$ and $\alpha+\beta$ to $\beta$ transformation temperatures, ductility, the effect of hydrogen and oxygen on residual cladding ductility, integral quench tests for strength, ballooning, burst, oxidation, fuel relocation and possible fracture at quench have been further investigated. All these data are also used for validation of transient fuel performance computer codes (Lyon et al., 2004).

After these studies, the NRC is considering a rulemaking that would revise requirements in $10 \mathrm{CFR}$ 50.46 (the ECCS rule), because the current regulatory acceptance criteria are not made for high burnup fuel. Currently the embrittlement mechanisms are not contemplated and the $17 \%$ limit on oxidation is not adequate to preserve the level of ductility that the NRC originally chose to be adequate for protection. 
The rule is expected to be more restrictive than the current rule and the industry will need to comply with the new rule within the following four to six years, usually this is the time between the proposal and the final approval.

Now, at the state of technology, we are able to manage a multi physics analysis and perform calculations to offer a potential solution to the LOCA problem with the new 10 CFR 50.46 rule.

The primary aim of this study is to lay out a roadmap to demonstrate the application of the new methodology. Therefore, some steps have been simplified (the fuel performance parameters calculation) or not described in detail in this paper (uncertainty quantification), as discussed in the next sections.

\section{Problem Definition}

The most of Large Break LOCA Analysis of Record (AORs) in the US are licensed using the BEPU approach. Therefore, this study is dedicated to those types of analyses, but intermediate and small break LOCA scenarios are also significantly impacted by the new rule.

As already mentioned, the previous rule defined, among other things, the Peak Cladding Temperature $\mathrm{PCT}<2200^{\circ} \mathrm{F}(1477 \mathrm{~K})$ and the Maximum Local Oxidation $\mathrm{MLO}<17 \%$.

Due to all the tests of the zirconium-alloy cladding materials conducted in the U.S. through the NRC's LOCA research program (U.S. NRC DG-1262; U.S. NRC DG-1261), the Draft Regulatory Guide (U.S. NRC DG-1263; Borchard and Johnson, 2013) has defined new acceptable analytical limits. The previous limit of $17 \%$ MLO will be substituted by an analytical limit, the Equivalent Cladding Reacted (ECR), defined as the total thickness of cladding that would be converted to stoichiometric $\mathrm{ZrO}_{2}$ from all the oxygen contained in the fuel cladding as $\mathrm{ZrO}_{2}$ and the oxygen in solid solution in the remaining metal phase. As shown in Fig. 1, the ECR limit is function of the cladding hydrogen pickup ratio before the LOCA accident.

The Peak Cladding Temperature limit when the pre-transient hydrogen content is less than $400 \mathrm{ppm}(\mathrm{w})$ is still the same, $2200^{\circ} \mathrm{F}$. However the ECR limit significantly decreases as the fuel is irradiated in the core and the cladding hydrogen concentration increases. 


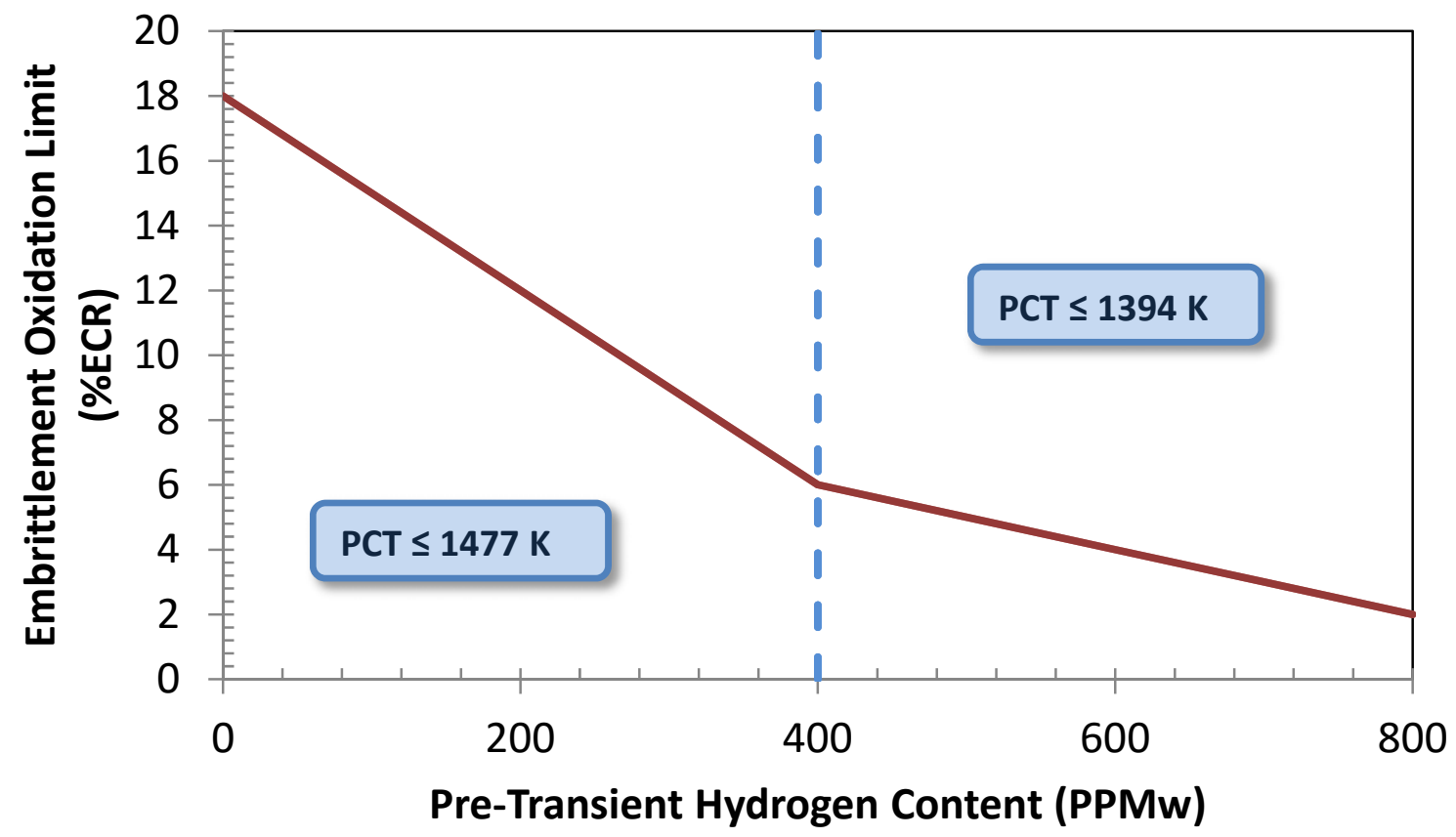

Figure 1 - CFR 50.46c proposed ECR limits according to the Draft Regulatory Guide DG-1263

The hydrogen content depends on the burnup value $(\mathrm{GWd} / \mathrm{Mt})$ and material characteristic of the cladding, as the performance to embrittlement under irradiation. In the present study, for a Zircalloy-4 cladding, the pre-transient hydrogen pickup content could be calculated in function of the fuel rod average by the following correlation (PWROG, 2011):

$$
\mathrm{H}=0.0035 \mathrm{BU}^{3}-0.1235 \mathrm{BU}^{2}+5.1073 \mathrm{BU}+21.075 \mathrm{ppm}(\mathrm{w})
$$

The correlation recommended for the estimation of the local cladding oxidation rate is the Cathcart and Pawel (Cathcart et al., 1977). This correlation follows a parabolic rate law:

$$
w_{O} \frac{d w_{O}}{d t}=0.1811 \exp \left(-\frac{39940}{R T}\right)
$$

Where $w_{o}$ is the total oxygen consumed in $\mathrm{g} / \mathrm{cm}^{2}, \mathrm{R}$ is the gas constant $(=1.987 \mathrm{kcal} / \mathrm{kmol} \mathrm{K})$ and $\mathrm{T}$ is the clad temperature $\mathrm{T}(\mathrm{K})$. This is converted in weight of clad reacted knowing that $w=2.85 w_{o}$ from the stoichiometry or the reaction $(2.85=91.2 / 32)$ : 


$$
\frac{w^{2}-w_{i}^{2}}{2}=1.471 \exp \left(-\frac{39940}{R T}\right) \cdot \Delta t
$$

Where $w_{i}$ is the initial weight $\left(\mathrm{g} / \mathrm{cm}^{2}\right)$ of the cladding (before the LOCA event). The integration is carried out knowing the clad temperature trajectory. The ECR (\%) is then computed from the following relationship:

$$
\operatorname{ECR}(\%)=\frac{w}{\rho_{Z r} \cdot s}
$$

Where $\rho Z r$ is the density of the Zirconium $\left(=6.50 \mathrm{~g} / \mathrm{cm}^{3}\right)$ and $s$ the original thickness of the cladding in $\mathrm{cm}$.

This new LOCA safety analysis involves several disciplines and, in order to obtain detailed information in a multi-physics space analysis within different disciplines connected, it was necessary to connect different codes able to perform the analysis. The disciplines involved in this analysis are:

- Thermal-Hydraulics

- Reactor Physics

- Fuel Performance

- Uncertainty Quantification

Respectively, the codes selected to lead the whole analysis are:

- RELAP5-3D (INL, 2012a)

- PHISICS (Rabiti et al., 2011)

- FRAPCON/FRAPTRAN (U.S. NRC, 2014a; U.S. NRC, 2014b)

- RAVEN (Alfonsi et al, 2013a)

All the codes are developed at the Idaho National Laboratory (INL) and new improvements have been also added by INL to perform such kind of analysis. (Alfonsi et al., 2013b; Alfonsi et al., 2014; Zoino et al. 2015).

In this initial methodological assessment, only thermal-hydraulics and reactor physics aspects will be addressed, using RELAP5-3D and PHISICS codes, respectively. The fuel performance quantities (e.g. Hydrogen Content, ECR, etc.) have been computed by the previously reported relationships, without 
using, at the present stage, the fuel performance codes FRAPCON/FRAPTRAN. The uncertainty quantification process has been performed at INL and details can be found in Szilard et al., 2015.

\section{Description of the analysis flow}

In order to integrate the Core Design into the LOCA analysis, the following approach has been used:

1. Reaching the equilibrium cycle: since the goal of this analysis is to show the methodological aspects that are involved in the reassessment of the safety margins for the current U.S. Nuclear Power Plant fleet, the LOCA analysis needs to be performed in a equilibrium cycle configuration (reasonably reached by all the current NPPs). The multi-cycle depletion evolution is led by PHISICS, receiving thermal-hydraulics feedbacks from RELAP5-3D, using the coupled suite PHISICS/RELAP5-3D. The boron concentration search (criticality) and the new developed capability of fuel shuffling manage the evolution of the operational cycles and the reloading patterns. The goal of this step is to identify the reference condition of fuel composition and power shape of the "equilibrium" cycle, which is the cycle in which the fuel-reloading pattern is almost constant (i.e. same composition and spatial loading of the fuel batches). The "equilibrium" cycle is the one during which the LOCA scenario is initiated. A restart is generated to perform a PRA analysis from this point.

2. Reaching the LOCA: from the restart file generated, another analysis is initiated at the "equilibrium" cycle conditions. During this cycle, multiple points in time are selected to initiate a load-following transient. The RAVEN code manages where and when the LOCA begins. Each condition of the system at the selected point in time is used as initial conditions for the loadfollowing analysis. The transition between the depletion evolution of the equilibrium cycle and the load-following is automatically performed using the developed "multi-deck" capability of the coupled suite PHISICS/RELAP5-3D. The load-following is performed because the core status during the cycle doesn't determine challenging conditions for LOCA analyses and, as already mentioned, it is necessary to assess safety margins for typical reactor operations. For this reason, such kind of analyses are generally performed considering the reactor right after a maneuver that can initiate, for example, a Xenon transient. In this case the power history is an input of the simulation. Cooling down the reactor, there is a reactivity insertion that is automatically compensated by the PHISICS code by a new capability implemented into the Criticality Search module, which is able to simulate the critical insertion of the control rods (control rods' criticality 
search). The goal of this step is to choose when and where the LOCA begin and to have a skewed power shapes for initiating LOCA analyses.

3. LOCA analysis: as during the cycle multiple points are picked, during the maneuver multiple points are selected to initiate the LOCA analysis, finding the worst conditions inside the time of the maneuver. The LOCA analysis is finally performed also sampling the uncertain parameters, which affect the accident sequence, through the RAVEN code and finding the limit surface between success and failure. The transition between the maneuver and the LOCA analysis is performed automatically using the "multi-deck" capability of the couple suite PHISICS/RELAP5-3D, moving at this time from the maneuver transient to the LOCA transient calculations.

The described steps of the analysis flow are summarized in Table 1.

Tab. 1 - Simplified analysis flow of the methodology

\begin{tabular}{llll}
\hline \multicolumn{1}{c}{ Analysis performed } & \multicolumn{1}{c}{ Goal } & \multicolumn{1}{c}{ Used tools } \\
\hline Step 1 & n cycles depletion evolution & $\begin{array}{l}\text { PHISICS/RELAP5-3D in multi- } \\
\text { reference exposure map } \\
\text { and power shape }\end{array}$ & $\begin{array}{l}\text { TH feedbacks, Boron } \\
\text { concentration search, fuel } \\
\text { shuffling and management }\end{array}$ \\
Step 2 & & & module)
\end{tabular}

The uncertainty quantification analysis with the RAVEN tools is not described in this paper. For details on the considered uncertainties, refer to Szilard et al., 2015. 
The simplified analysis here presented is a demo (a proof of concept) to show the potential of these new tools. It is different from the final analysis flow that will be used. The differences are:

- The most important missing step is the fuel performance calculations: FRAPCON is not yet coupled with the suite PHISICS/RELAP5-3D. It will be incorporated to provide accurate feedbacks of the fuel performance calculations into the RELAP5-3D model for steady-state initializations and also during the LOCA analysis, using FRAPTRAN and receiving feedbacks of the geometry changes. For this reason the ECR was manually calculated using the correlations reported in section 2, taking data from the main calculation of the suite PHISICS/RELAP5-3D.

- The probabilistic risk analysis (PRA) was not yet performed. RAVEN is already ready to perform such kind of analysis but only 8 points in time were selected (Step 2.1) to show just the methodologies: BOC, 50 days, 100 days, 200 days, 300 days, 400 days, 500 days, EOC have been used as initial conditions for the load-following analysis (Step 2.2).

- The LOCA RELAP5-3D model used was a six-channel core model. It was preliminary performed a transition from the 1-core channel/assembly model, used until the maneuver, to the 6 channel core model used for the LOCA analysis in Step 3.

\section{Fuel cycle analysis and core design}

The core design simulation strategy can be split in two phases (Fig. 2). The first one is behind the calculation: the generation of the homogenized neutron cross-sections is performed through a lattice code. The second phase is the reactor calculation: the reactor can be approximated by homogenized regions, where all the physical properties are considered homogenous. In the coupled suite PHISICS/RELAP5-3D, PHISICS is used to perform the neutron transport and the depletion calculations; on the other hand the thermal-hydraulic calculation is managed by RELAP5-3D. 


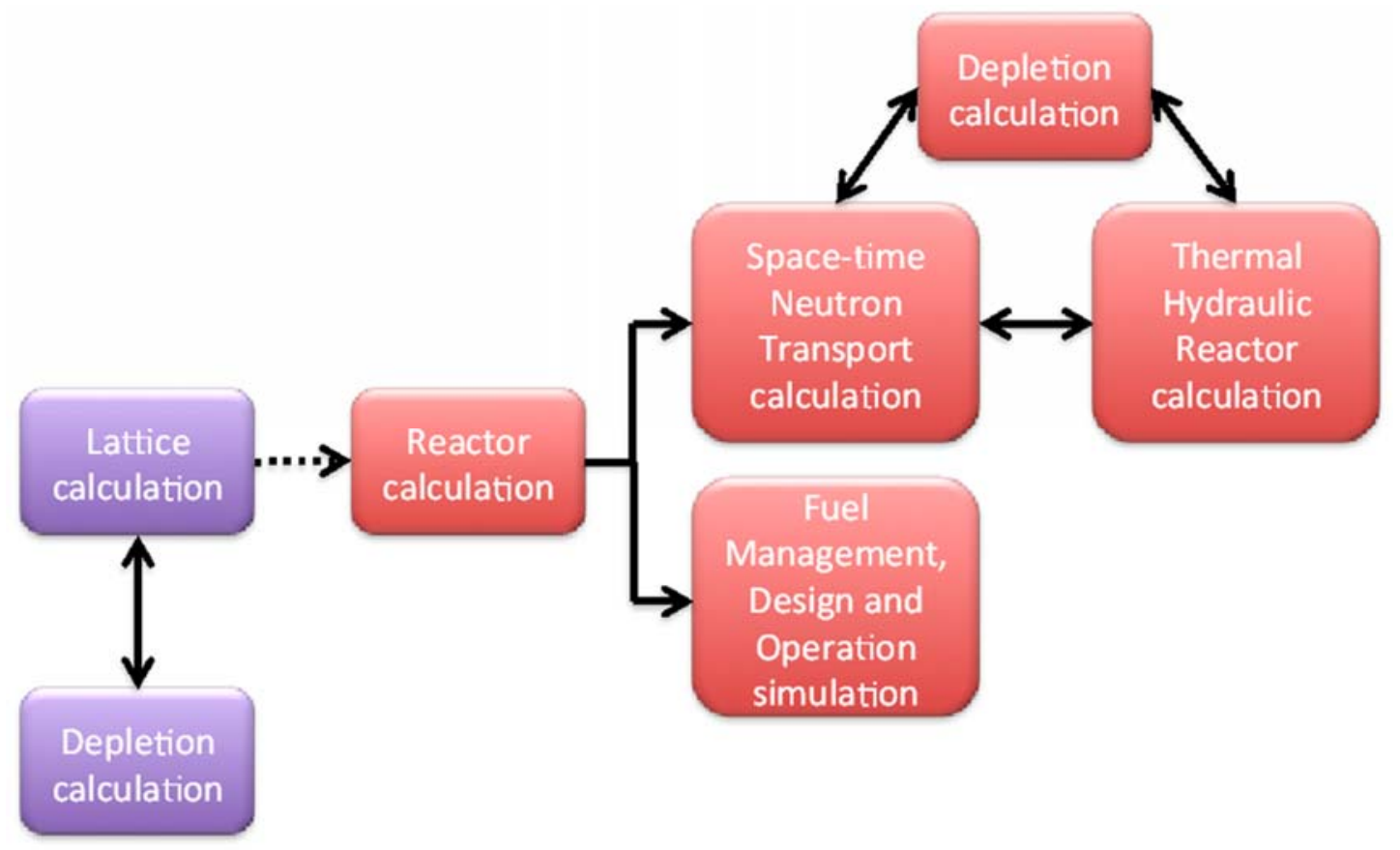

Figure 2 - Core Design Strategy Scheme

\subsection{Lattice physics and cross section generation}

To perform the lattice calculation was used one of the most popular lattice codes, the software HELIOS-2 (Wemple et al., 2011). HELIOS-2 has been extensively validated and has shown exceptional accuracy in both, traditional and non-traditional, cases. It can use two different methodologies to calculate the transport equation solutions, the first one is the method of the characteristics and the second one is the collision probability solver. Resonance self-shielding is calculated via the subgroup method, with a transport-based Dancoff calculation. The predictorcorrector method is used for depletion, and the depletion path allows arbitrary state changes, generalized decay capabilities, and branch-off calculations at any point in the solution path, in order to compute the flux solution for different combination of state variables.

In order to generate the homogenized neutron cross-sections, the calculation has been performed considering individually all the unique assemblies constituting the reactor core. It was taken in account all the different compositions, as the different enrichments, and the geometry discontinuities, as the grids and the neighbor assemblies. In order to reduce the computing requirements, the model was reduced to a $1 / 8$ core model exploiting symmetries. The flux solution found was then used to perform 
an energy-space collapsing to compute the homogenized neutron cross sections. Each lattice calculation was performed considering all the different combination of the state variables that characterize the reactor of the simulation: burn-up, fuel temperature, moderator density and boron concentration.

\subsection{Reference core design}

The adopted reference plant is a typical Pressurized Water Reactor core, whose layout and main parameters are shown in Fig. 3 and Table 2, respectively. The model layout is based on the "Benchmark for Evaluation And Validation of Reactor Simulations (BEAVRS)" (Horelik et al., 2013). BEAVRS is a detailed PWR benchmark containing real plant data for the first 2 operational cycles. It is usually used to evaluate the accuracy of reactor physics simulation tools.

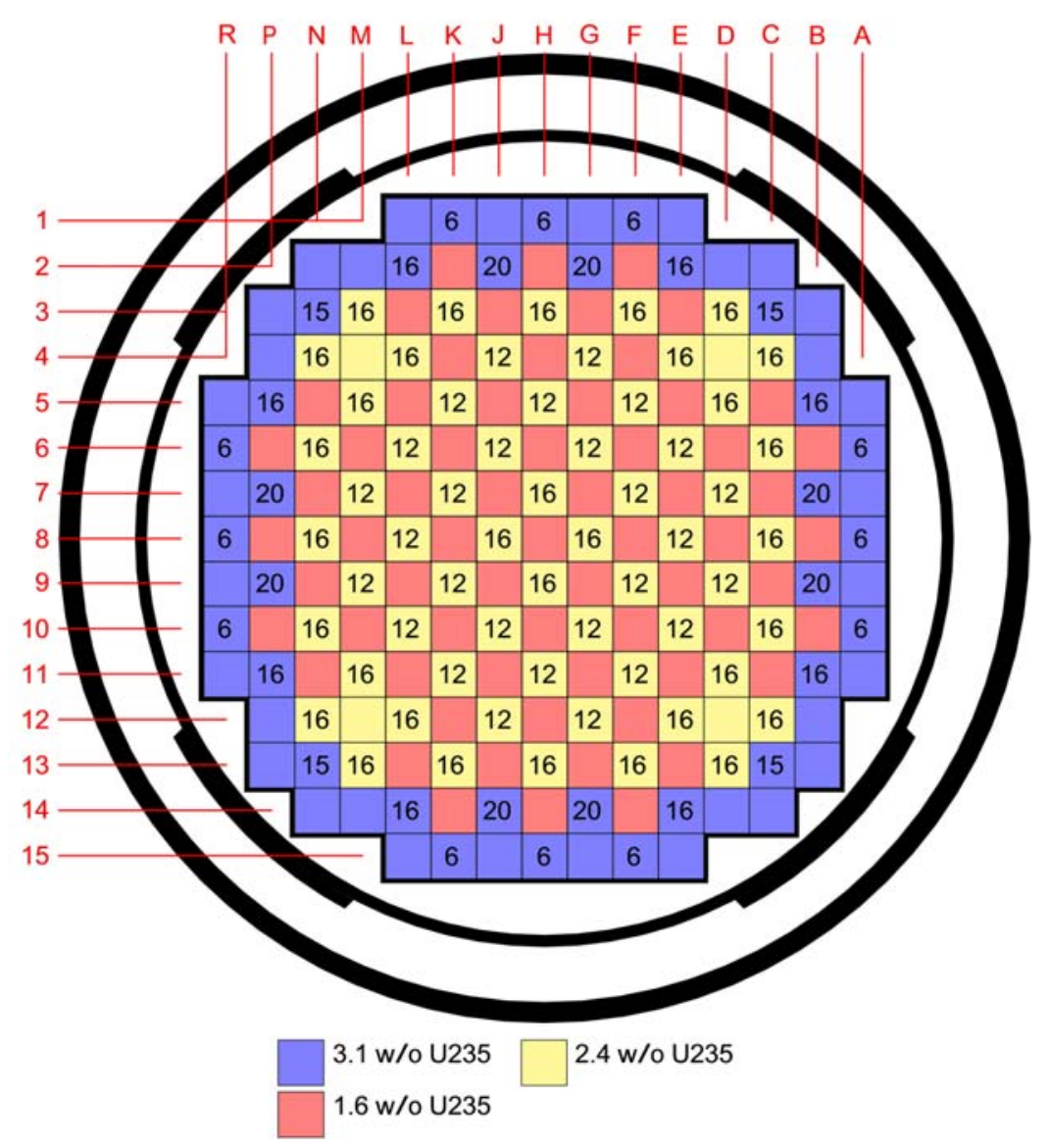


Figure 3 - Reactor Core Layout (Horelik et al., 2013)

Table 2 - Key plant parameters

\begin{tabular}{|c|c|}
\hline \multicolumn{2}{|c|}{ Core Lattice } \\
\hline No. Fuel Assemblies & 193 \\
\hline Loading Pattern & U-235 w/o \\
\hline Region 1 & $1.61 \%$ \\
\hline Region 2 & $2.40 \%$ \\
\hline Region 3 & $3.10 \%$ \\
\hline \multicolumn{2}{|c|}{ Control } \\
\hline Control Rod Material & Ag- $80 \%-$ In- $15 \%-$ Cd- $15 \%$ \\
\hline No. Control Rod Banks & 57 \\
\hline No. Burnable Absorber Rods in Core & 946 \\
\hline Burnable Absorber Material & Borosilicate Glass, $12.5 \mathrm{w} / \mathrm{o} \mathrm{B}_{2} \mathrm{O}_{3}$ \\
\hline \multicolumn{2}{|c|}{ Performance } \\
\hline Power & 3411 MWth \\
\hline Operating Pressure & $15.51 \mathrm{MPa}$ \\
\hline Isothermal Coolant Temperature & $564.82 \mathrm{~K}$ \\
\hline
\end{tabular}

Using the "proximity" approach and exploiting symmetries, 64 different cross section libraries have been identified with different composition, structural material, instrumentation tube locations and different neighbors. This approach led to the creation of 29 different cross section sets for the fuel region and 1 for the radial reflector (Fig. 4), composed by the baffle, water between the baffle and the barrel, the barrel and the thermal shield. With the same approach 30 cross section libraries have been created for the layers where the grids are located. Finally, other 4 cross section sets have been generated to modelling the assembly extremities, the bottom reflector and the top reflector, considering the presence of the control rod banks completely extracted. In total 64 cross section libraries have been used during the calculation. As already mentioned, the lattice calculations are generally employed in starting from pre-collapsed multi-group neutron energy structure. For the computation of the different cross sections sets, the lattice calculation has been performed starting from a 44-energy group structure, then collapsed into an 8 groups structure in the homogenization procedure. In Table 3 the collapsed energy structure is reported. 


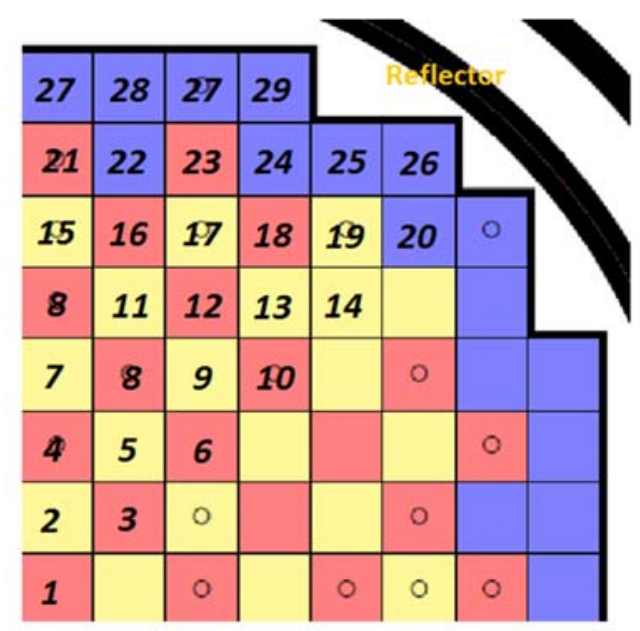

Figure 4 - Geometric location of cross section libraries

Table 3 - Collapsed energy structure

\begin{tabular}{ccccccccc}
\hline Group & 1 & 2 & 3 & 4 & 5 & 6 & 7 & 8 \\
\hline $\begin{array}{c}\text { Upper Energy Bound } \\
(\mathrm{eV})\end{array}$ & $2.0010^{7}$ & $2.2310^{6}$ & $8.2110^{5}$ & $9.1210^{3}$ & $1.3010^{2}$ & 3.93 & 0.625 & 0.146 \\
\hline
\end{tabular}

As already mentioned, the cross sections sets have been created with respect to 4 state variables in order to exchange feedbacks between PHISICS and RELAP5-3D. For the scope of this work, the tabulation points shown in Table 4 have been selected, bringing to a N-Dimensional grid of 80 tabulation points for the cross sections.

Table 4 - Tabulation points of cross sections

\begin{tabular}{lllll}
\hline Boron concentration $(\mathrm{ppm})$ & $1.010^{-6}$ & 1000 & 1900 & \\
Moderator density $\left(\mathrm{kg} / \mathrm{m}^{3}\right)$ & 640.8 & 833.04 & 945.18 & 1000.0 \\
Fuel temperature $(\mathrm{K})$ & 573.5 & 1073.5 & 1573.5 & \\
Burn-up $\left(\mathrm{GWd} / \mathrm{t}_{\mathrm{HM}}\right)$ & 0.0 & 0.15 & 45.0 & \\
\hline
\end{tabular}

A real important remark should be considered carefully, as the homogenized cross sections were calculated by the lattice code HELIOS-2 with the "proximity" approach. This approach led to the identification of 64 different cross sections calculated on the first cycle. In a multi-cycle analysis as the 
present one, this approach is not correct, because the core design layout changes. Indeed, homogenized cross sections should be recalculated for each reloading patterns, regarding the new neighbors of each assembly. In this analysis this issue was also amplified because to perform the analysis on a modern reloading patterns (sect. 4.3.1), this is representative of a gradual migration from a "high-leakage/lowenergy" to a "low-leakage/high-energy" reloading pattern. Starting from the second cycle, homogenized cross sections weren't recalculated and the same cross sections were used for all the cycles, trying to take the most analogue in terms of neighbors, enrichments and burnable absorbers. This study is a proof of concept; the final goal was to show new strategy approaches and methodologies, accepting a certain level of approximation in the obtained results.

\subsubsection{Thermal-hydraulic nodalization}

In order to obtain efficiently the data for the LOCA analysis from the first $n=10$ cycles, the equilibrium cycle and the maneuver, the primary and the secondary system were excluded from the thermal-hydraulic nodalization because they were not active components. The thermal-hydraulics model of the reactor has been created considering the reactor core only. The primary system has been modeled considering the upper and lower plenum of the core only. The RELAP5-3D nodalization (Fig. 5). has been built using one core channel per fuel assembly, 193 in total. The radial reflector has been modeled as a bypass channel that bypasses the $6 \%$ of the mass flow. Each core channel is mapped with a single kinetic zone (x-y) and 18 axial kinetic layers. Radially 257 kinetic zones have been defined, 193 for the assemblies and the others in periphery. The kinetic model is constituted of 4626 kinetic zones in total. 


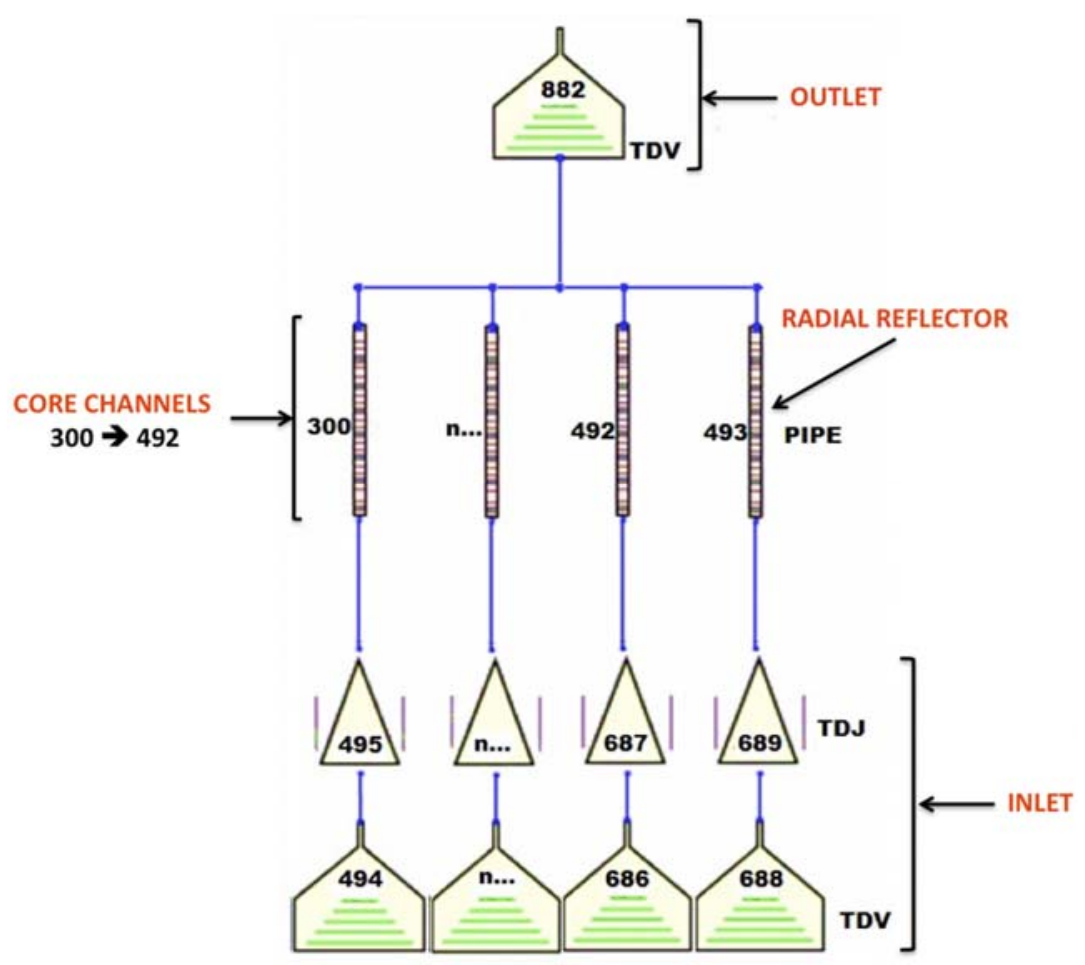

Figure 5 - RELAP5-3D Core nodalization.

\subsection{Multi-Cycle Strategy}

The reactor evolution has been followed for 10 operational cycles, until reaching the reference equilibrium one (supposedly nowadays reached by all the existing operative reactors in the US). The equilibrium cycle might be "reached" after several reloads ( 20-30). In the study the 11th cycle is considered to be equivalent to the equilibrium cycle.

In order to reach a typical cycle length of 18 months, the initial BEAVERS fuel enrichments (corresponding to a 12 months operation) have been increased.

\subsubsection{Reloading Patterns}

As described, a modern reloading pattern and the life of the reactor have been used in this study, representing a gradual migration from a high-leakage or low-energy reloading pattern to a low-leakage or high-energy one. 
The first and the second reactor layouts and, therefore, the first reloading pattern are constructed based on the data reported in the BEAVRS benchmark (Horelik et al., 2013), shown in Fig. 6
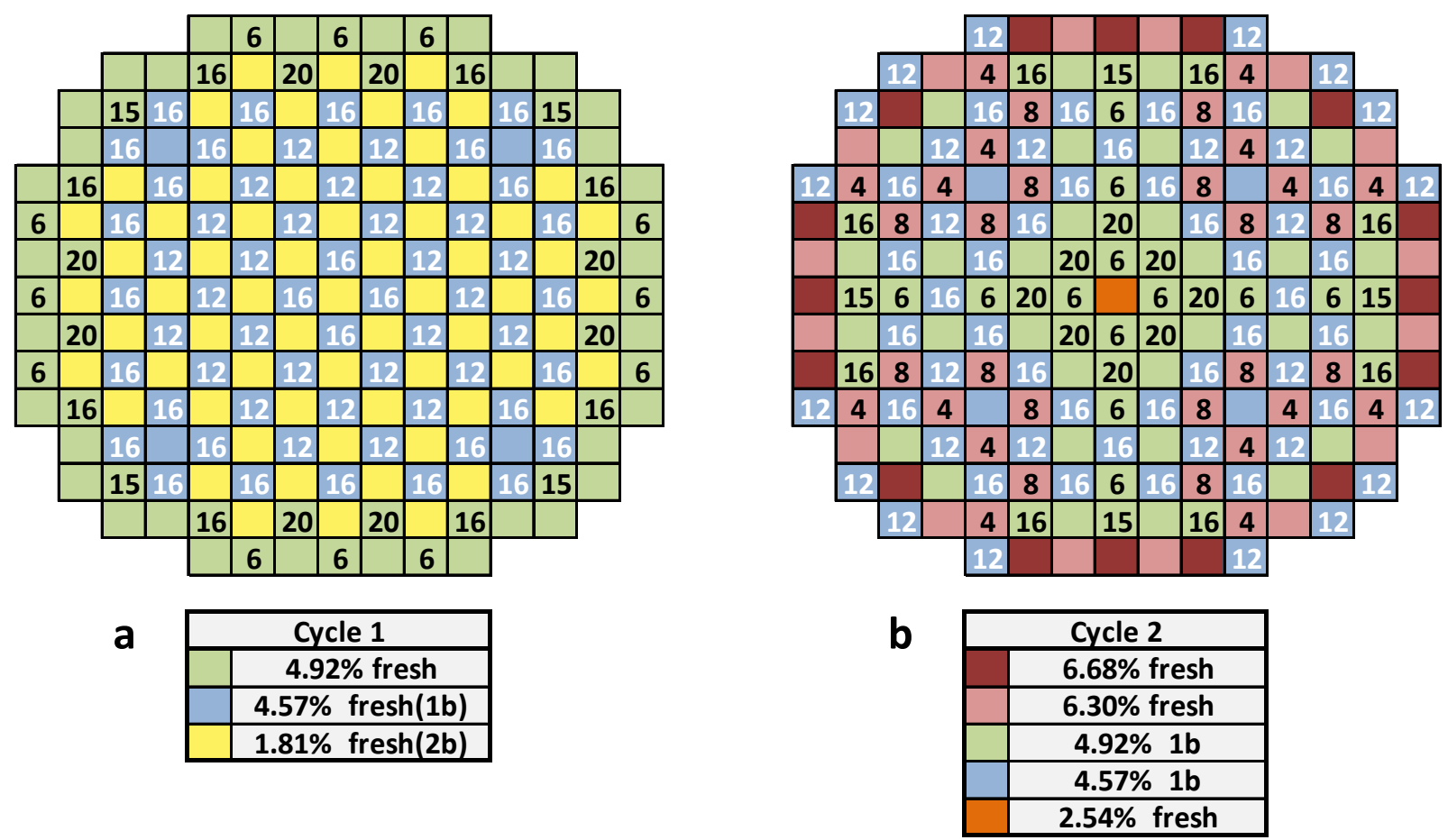

Figure 6 - a) $1^{\text {st }}$ Cycle and b) $2^{\text {nd }}$ Cycle Reloading Patterns.

Starting from the $3^{\text {rd }}$ cycle, the fresh fuel assemblies are located in the same positions in the core, however the moves (shuffling) inside the core had been changed because the burnt assemblies were different for positions and enrichments (Fig. 7 and Fig. 8) 

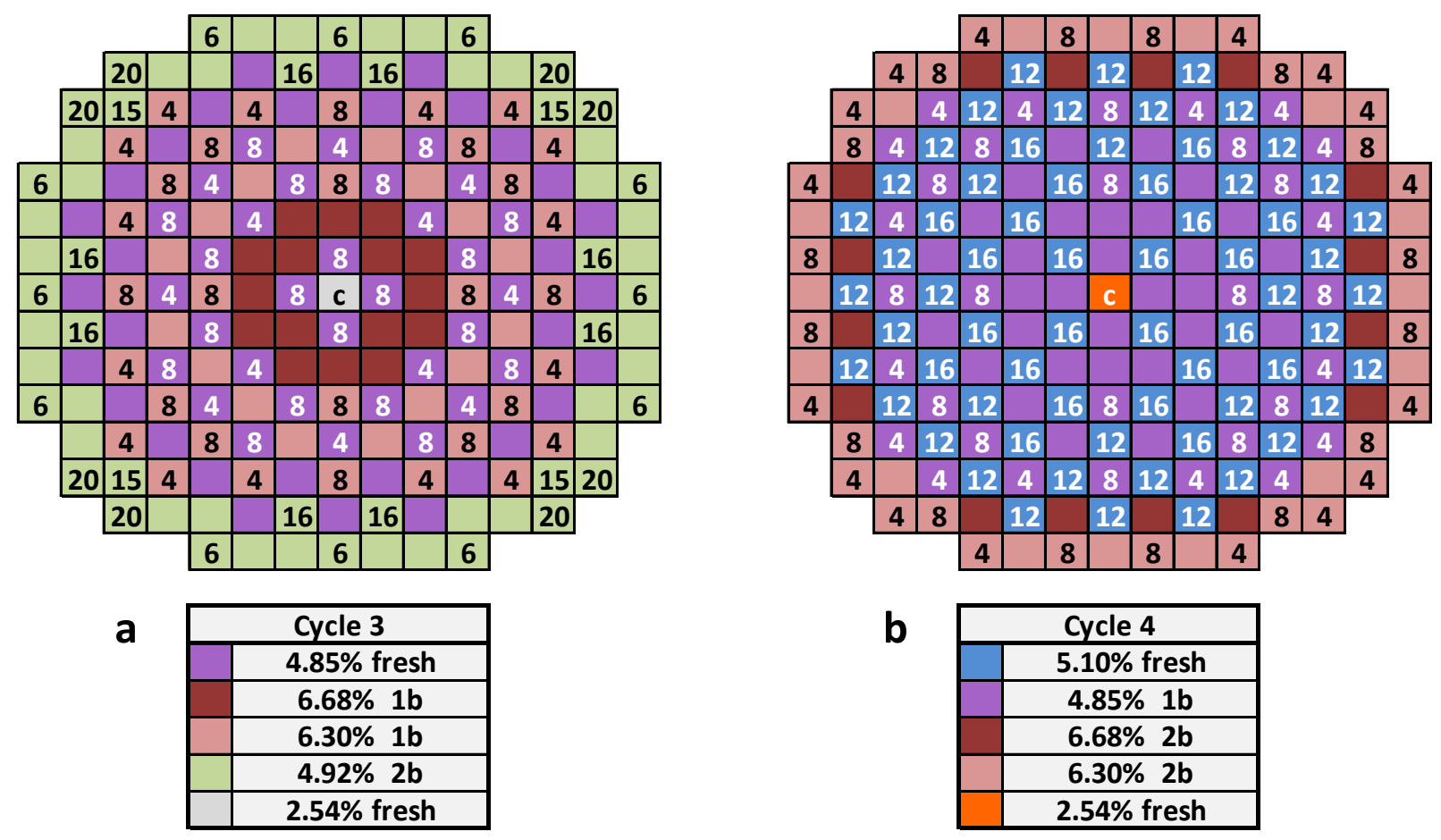

Figure 7 - a) $3^{\text {rd }}$ Cycle and b) $4^{\text {th }}$ Cycle Reloading Patterns.
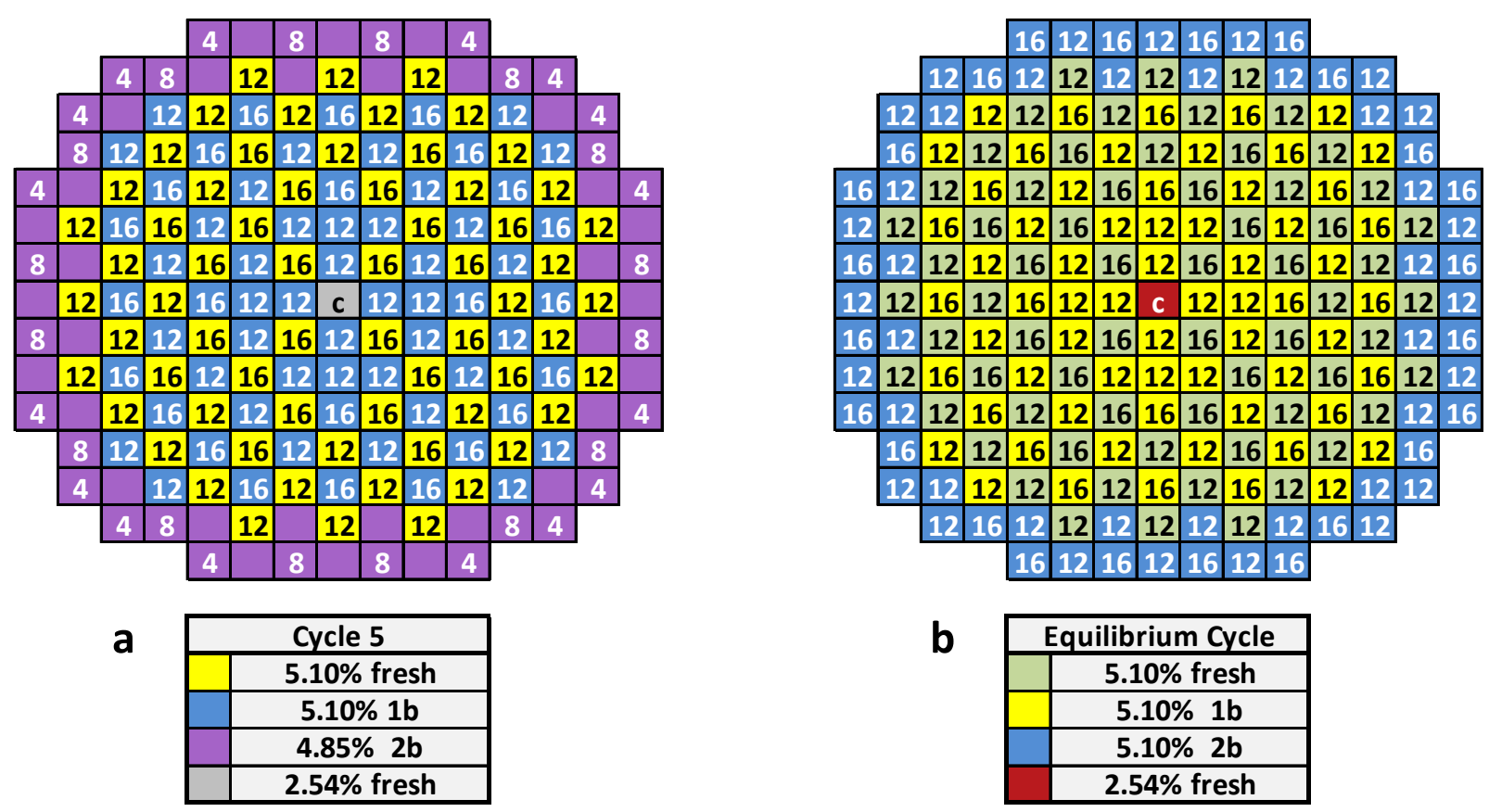

Figure 8 - a) $5^{\text {th }}$ Cycle and b) $\mathrm{N}^{\text {th }}$ Cycle Reloading Patterns. 
From the $6^{\text {th }}$ cycle to the $10^{\text {th }}$ cycle enrichments and layouts are the same; the analysis has been led for other 4 cycles with the same configuration to stabilize the reactor and to reach a strong $1 / 8$ symmetry.

All the 10 cycles and the equilibrium cycle swing between 525 and 555 days, 18 months plus or less 15 days.

As mentioned, the cross section set of the first cycle has been used for all the cycles, even if, a rigorous approach would have led to the re-computation of the cross-section sets for each reloading pattern. For this reason, the fresh fuel enrichment in the equilibrium cycle is $\sim 5.1 \%$, higher than what expected for an operational 18-months PWR, usually around $\sim 4.8 \%$.

\subsubsection{Boron Concentration Evolution}

During the execution of the reactor depletion evolution (operational cycles) the PHISICS code can optionally employ a criticality search approach (Criticality Search Module, Alfonsi et al., 2012), in which some user-defined densities (and/or state variables) can be adjusted in order to maintain the reactor critical.

In this case, the criticality search has been performed on the tabulation field variables named "PPM" (representing the boron concentration). The Criticality Search Module adjusts tabulation PPM in order to obtain keep the reactor critical and when its value fells below $5 \mathrm{ppm}$, a new cycle is automatically initiated, calling the SHUFFLE Module and applying the defined reloading pattern for that cycle. Fig. 9 shows the boron evolution for all the 10 cycles. It can be noticed, as already mentioned, that the end of cycle for all the simulated cycles is $\sim 18$ months \pm 15 days. Peaks boron concentration at Begin Of Cycle (BOC) changes in relation of specific cycle core layouts, being below $2000 \mathrm{ppm}$ in all the cycles. This is crucial because 2000 ppm is the critical value at which void reactivity coefficient can become positive. The maximum boron concentration is quite high due to the high enrichments adopted because, as already mentioned, cross sections had not been recomputed. 


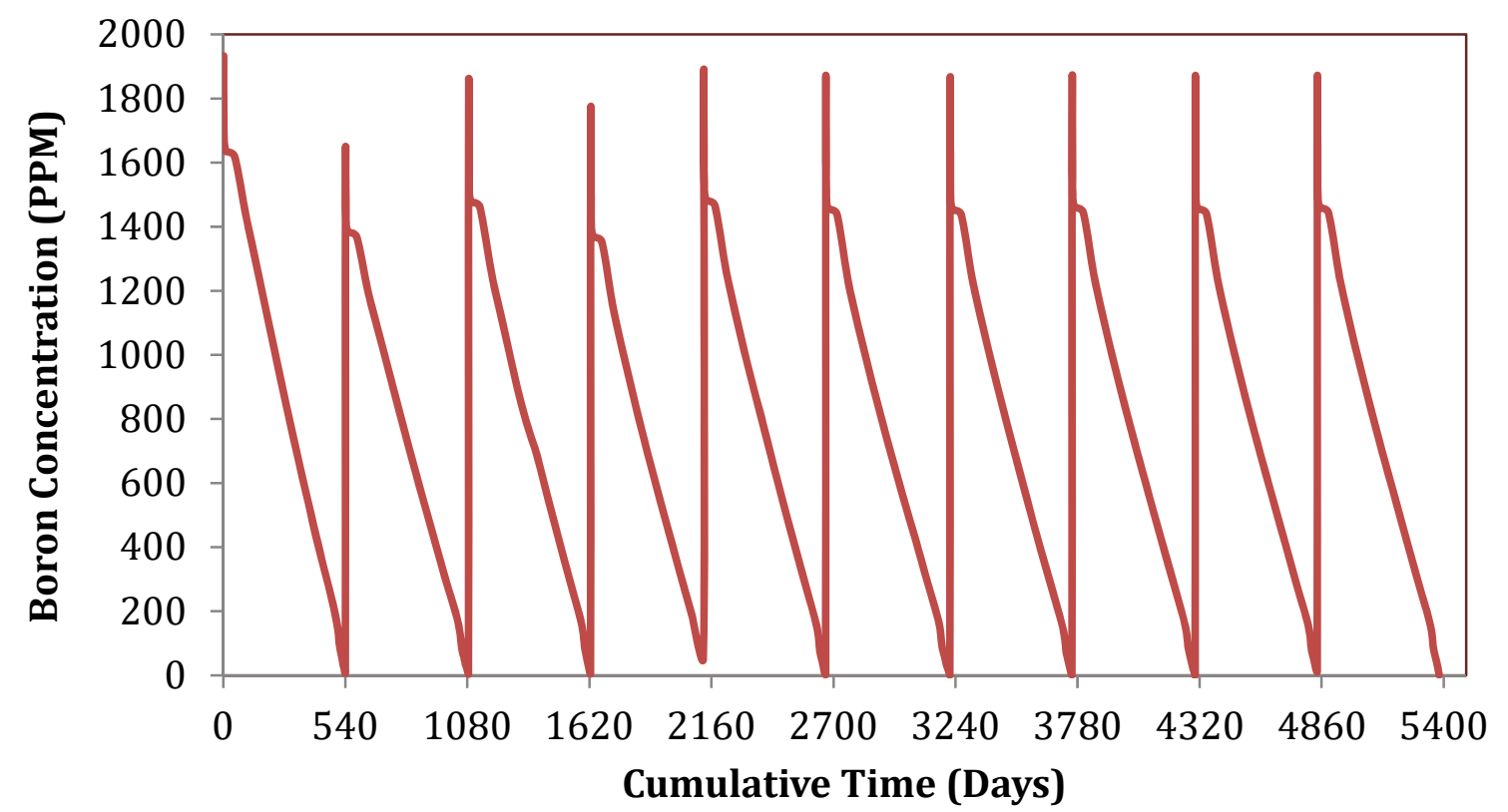

Figure 9 - Boron Concentration Evolution

\subsubsection{Power shape and peaking factors}

The power shapes during the 10 cycles change significantly for the migration from the high-leakage to the low-leakage configuration. It is also significant the power shape flattening from the BOC to the EOC for each cycle.

The first cycle is a high-leakage configuration, which is the best on the neutronic aspect. The assemblies' configuration used has been the same of BEAVRS, but enrichments were higher to reach an $18^{\text {th }}$ months length. The assembly-wise integrated power is flatted and peaking factors are lower than the other configurations. However modern reloading patterns are made with a low-leakage configuration to prevent the pressure vessel embrittlement by radiations (Perrin, 1993). For this reason, a low leakage configuration has been chosen for the equilibrium cycle.

Determining radial peaking factors and axial peaking factors is an essential task in a LOCA analysis, in order to identify assemblies in different thermo-hydraulics conditions. An important point in this analysis is that the hottest assembly could change during the reactor life. Furthermore, at the BOC with fresh fuels, the peaking factors result more piqued (Fig. 10). During the cycle, with the power shape 
flatting, they are going to decrease significantly. Radial peaking factors are quite high (Table 5) because the cross section libraries had not been recomputed.

A Thermal Conductivity Degradation model (S. Ryu et al., 2015) has not been used in this proof of concept analysis. For this reason, in conjunction with the approximation on the neutron cross-sections, the peaking factors' distribution and magnitude are expected to be different in future results.

Table 5 - Peaking factors at BOC, MOC and EOC

\begin{tabular}{cccc}
\hline & BOC & MOC & EOC \\
\hline Radial Peaking Factors & 1.73 & 1.62 & 1.50 \\
Axial Peaking Factors & 1.39 & 1.30 & 1.27 \\
Total Peaking Factors & 2.40 & 2.10 & 1.90 \\
\hline
\end{tabular}

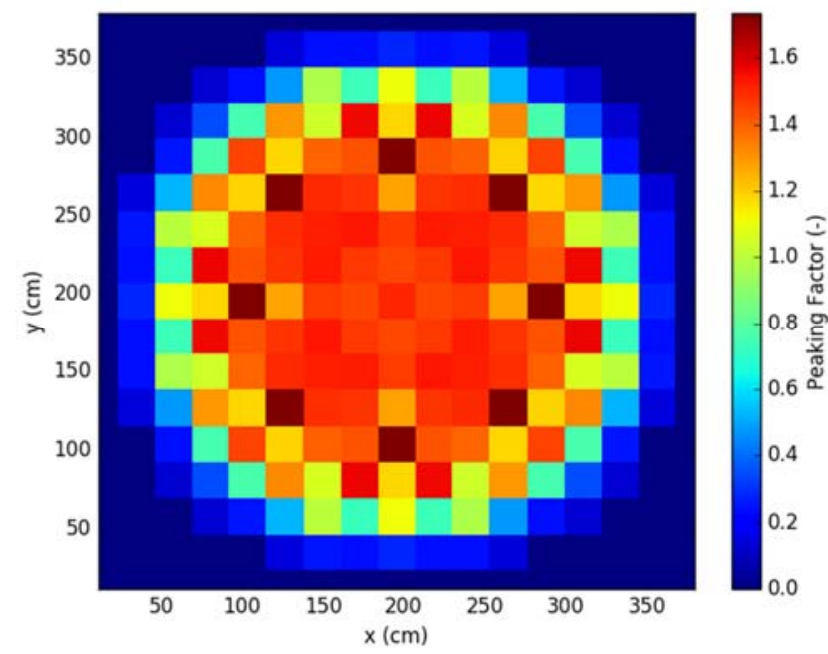

a) BOC radial PF

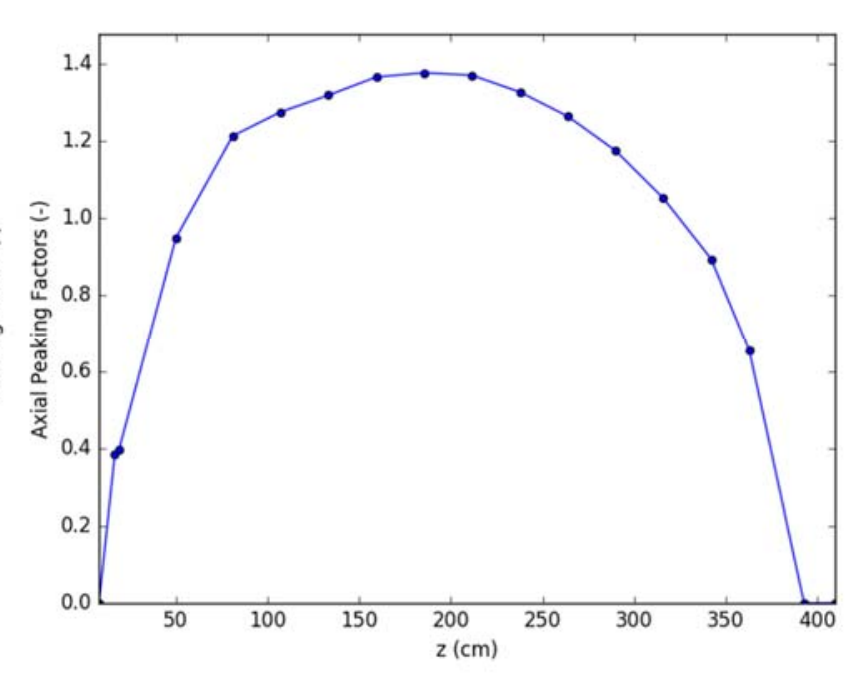

b) BOC axial PF 


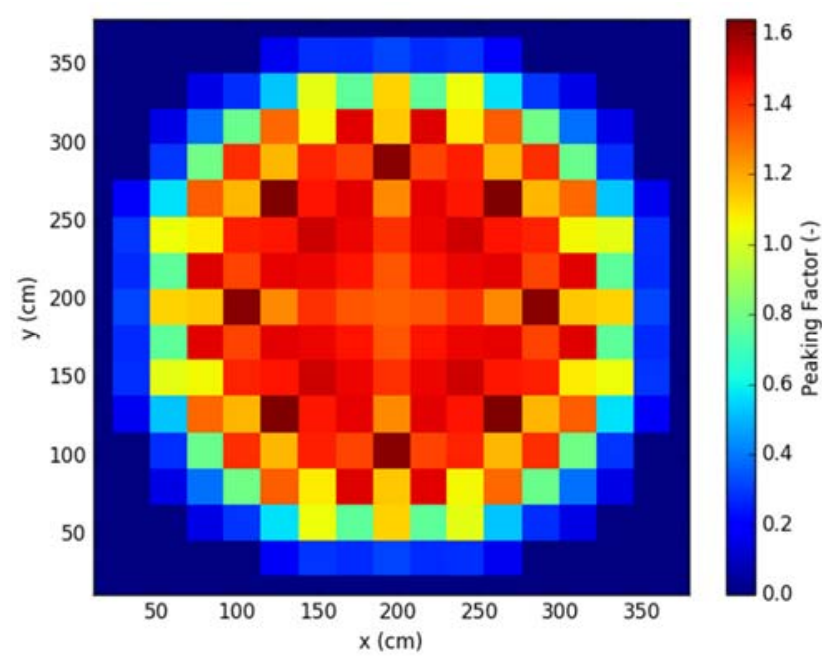

c) MOC radial PF

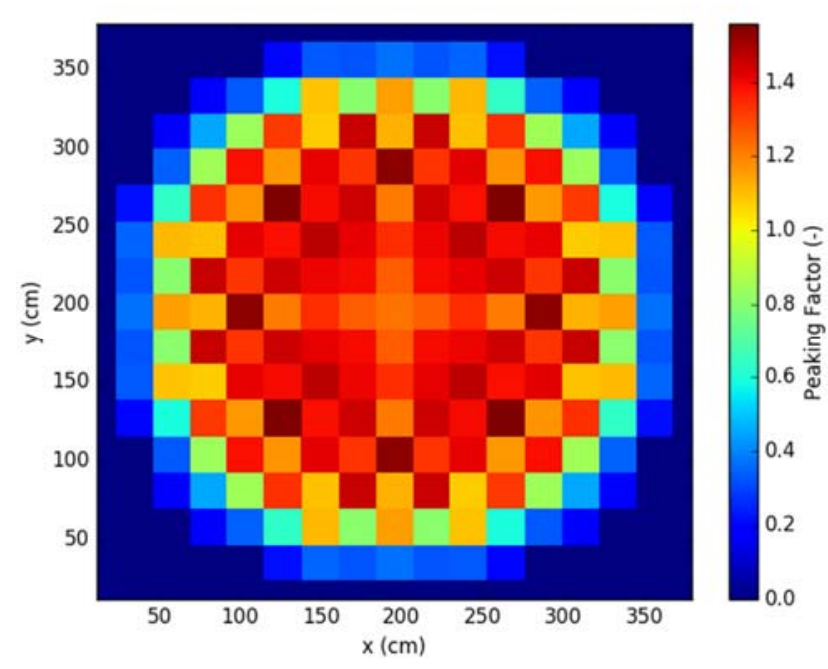

e) EOC radial PF

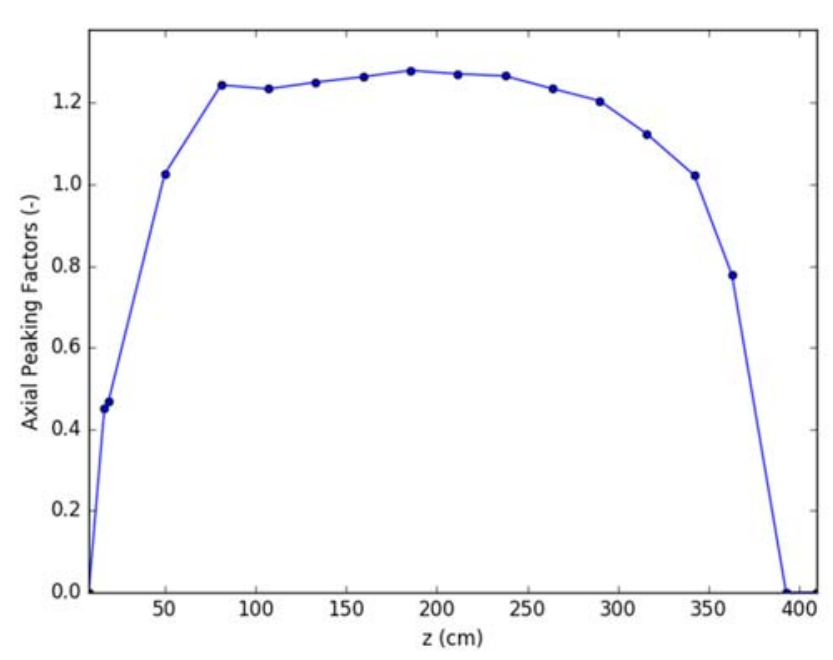

d) MOC axial PF

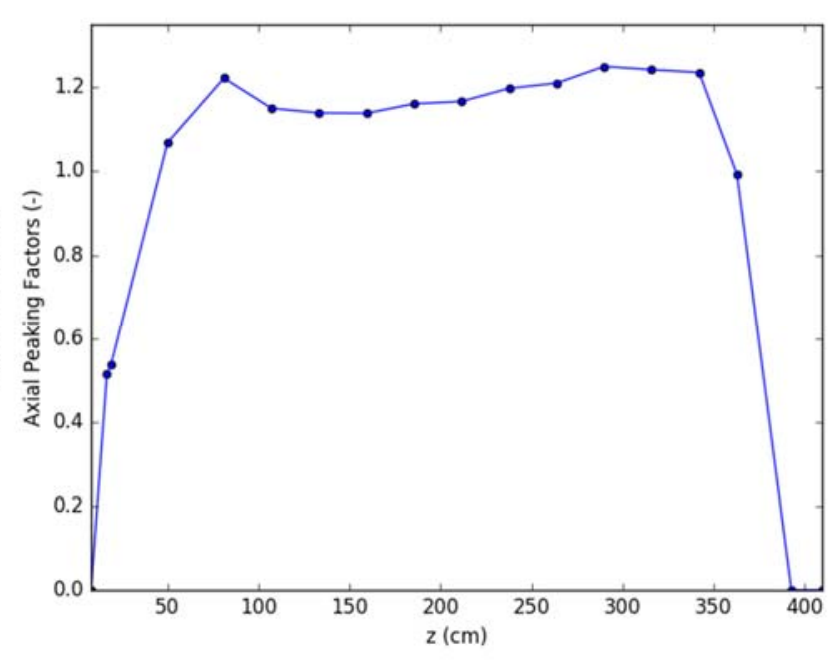

f) EOC axial PF

Figure 10 - Radial and axial peaking factors for equilibrium cycle at BOC: a) and b), MOC: c) and d), EOC: e) and f)

\subsubsection{Burn-up evolution}

Another key point of the new approach for this new LOCA analysis is the evaluation of the average burn-up in each assembly, which strongly impacts the cladding oxidation phenomena and can affect the identification of the most damaged assembly. 

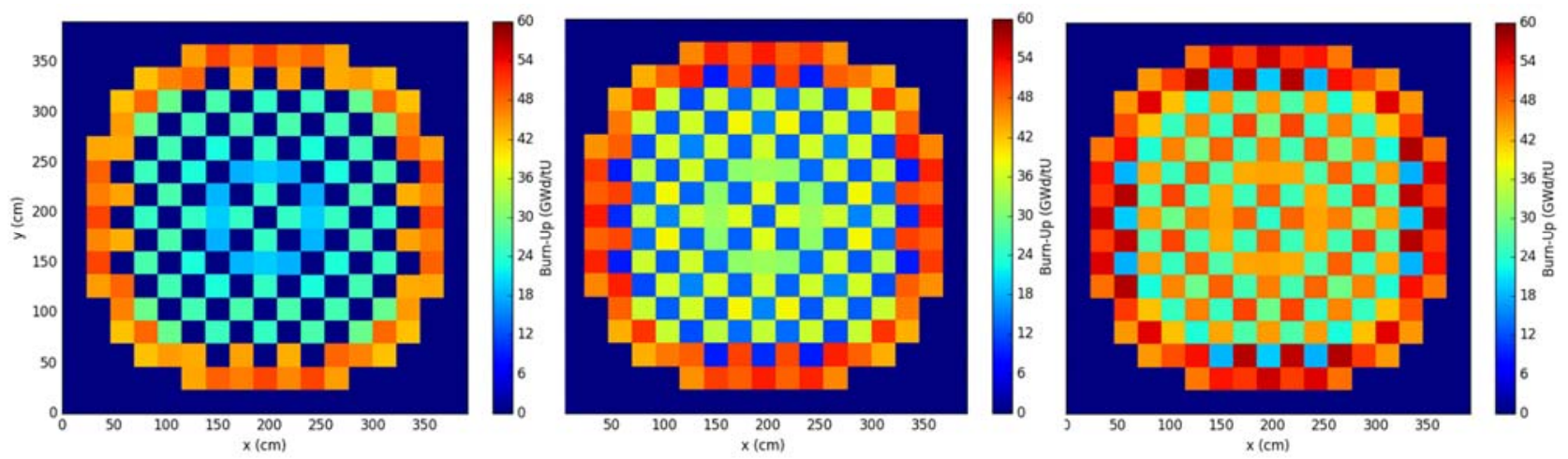

Figure 11 - BOC, MOC and EOC axially averaged assembly burn-up summary (GWd/tU).

Fig. 11 shows the assembly-averaged burn-up at BOC, MOC and EOC for the equilibrium cycle. The maximum average burn-up in this simulation was $58 \mathrm{GWd} / \mathrm{tU}$, below the general accepted limit of 65 $\mathrm{GWd} / \mathrm{tU}$. Assemblies that are affording the $1^{\text {st }}$ cycle reach the burn up of $25 \mathrm{GWd} / \mathrm{tU}$ at EOC. After, they face the $2^{\text {nd }}$ cycle changing position in the core and reaching the burn up of $45 \mathrm{GWd} / \mathrm{tU}$ at the end of it. Finally during the $3^{\text {rd }}$ depletion, the last 18 months, they reach the maximum burn up of about 58 $\mathrm{GWd} / \mathrm{tU}$. The depletion during the $3^{\text {rd }}$ assembly's life is less heavy because the assemblies are located in periphery.

\subsection{Xenon Transient Strategy}

The core status during an operational cycle does not determine challenging conditions for a LOCA analysis. For this reason, the BEPU analysis are generally performed introducing safety margins as penalizations. To conduct this analysis obtaining safety margins, it was introduced a maneuver that initiated a Xenon transient. The selected maneuver was a load-following operation of the reactor. During this maneuver the power history has been an input of the simulation. There was a reactivity insertion due to the cooling down of the reactor. The reactivity insertion was automatically compensated by PHISICS, using a new control rods insertion model in the Criticality Search module. The target was to skew the power shape with the control rods insertion to increase the peaking factors.

All the control rods created are located in assemblies made up of fresh fuel pellets. The control rods are gathered into 4 different banks. The locations of the control rods and the grouping of them is shown in Fig. 12. The different banks get inserted in timing and the chronological sequence is reported in the Fig. 12 as well. The first bank is going to be inserted until half of its length and, when half of it 
is already inserted, the bank two start to get inserted contemporaneously, while the first one complete its run and so to follow the other banks.

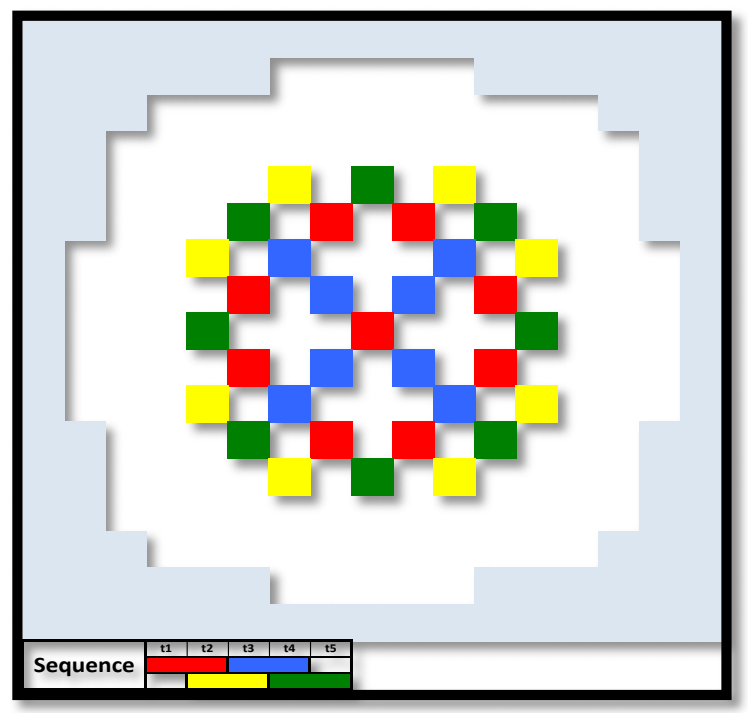

Figure 12 - Control rod banks, location and temporally insertion

\subsubsection{Load-Following Operation}

As already mentioned, a load-following has been chosen as maneuver in this study and the power history has been an input of the simulation in this step. The power had been changed at least every hour from $100 \%$ to $90 \%$ in a first phase. Then the power was rapidly raised up until $103 \%$ and finally it came back to $100 \%$, as in Fig. 13

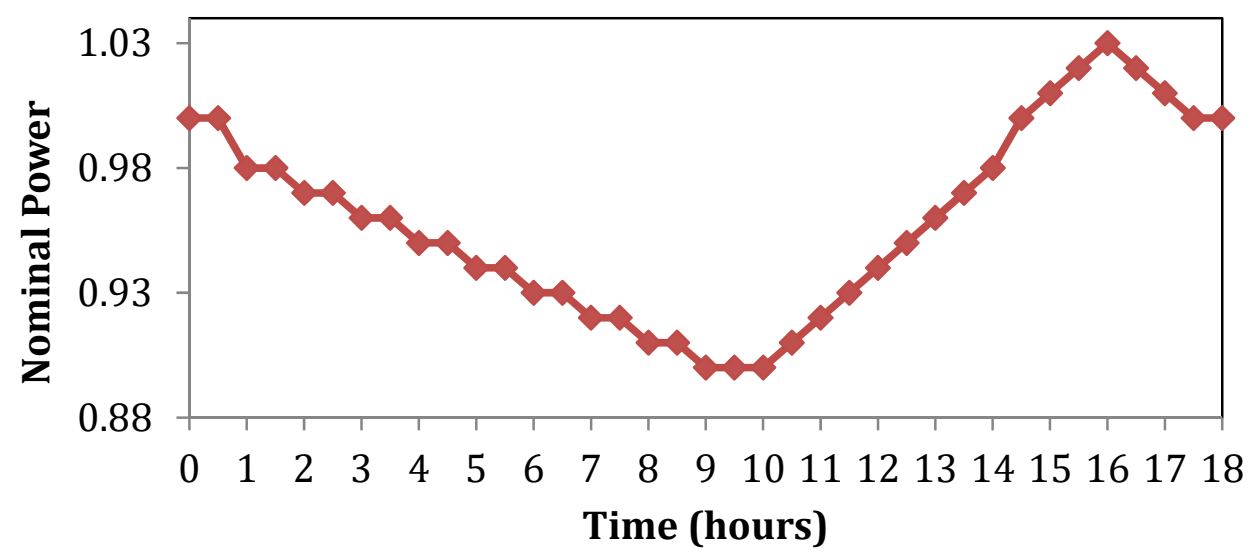

Figure 13 - Power history of load-following maneuver 
The Xenon had been crucial during the second phase of the load following. When power had been raised up to $100 \%$, control rods should come back to the initial position. But Xe-135 concentration has decreased under the initial concentration and reactivity insertion has still been positive. This because increasing power the flux had been burned more Xe-135 and because the reactor had produced less parent isotopes during the under-power phase. For this it was possible to raise power over the $100 \%$ and kept control rod banks inserted.

\subsubsection{Power Shape and peaking factors after maneuver}

For this study should be taken the worst condition during the maneuver. A dangerous condition has been found at the end of maneuver, when the power is come back to $100 \%$ and peaking factors are raised up. Anyway a rigorous approach should be to sample points through RAVEN during the maneuver, but in this demonstration study the adopted simplifications can be acceptable.

The power shapes had been changed significantly after maneuver. The maneuver started from the BOC used almost all the control rod banks. The control rods were fully inserted and for this reason the power shape has been changed more radially then axially. On the other hand, when the maneuver started from the EOC, just the first control rod bank has been inserted. Due this the power shape has been hardly changed axially and results very skewed.

To determine challenging conditions for the LOCA analysis scenarios is significant to determine the new radial peaking factors and the new axial peaking factors, to calculate the new total peaking factors and to identify the hot channel and the hot spot. Changing the power shape, the peaking factors had been raised up and they determined challenging conditions for the LOCA analysis scenarios (in Fig. 14 the radial peaking factors and in Fig. 15 the axial ones). 


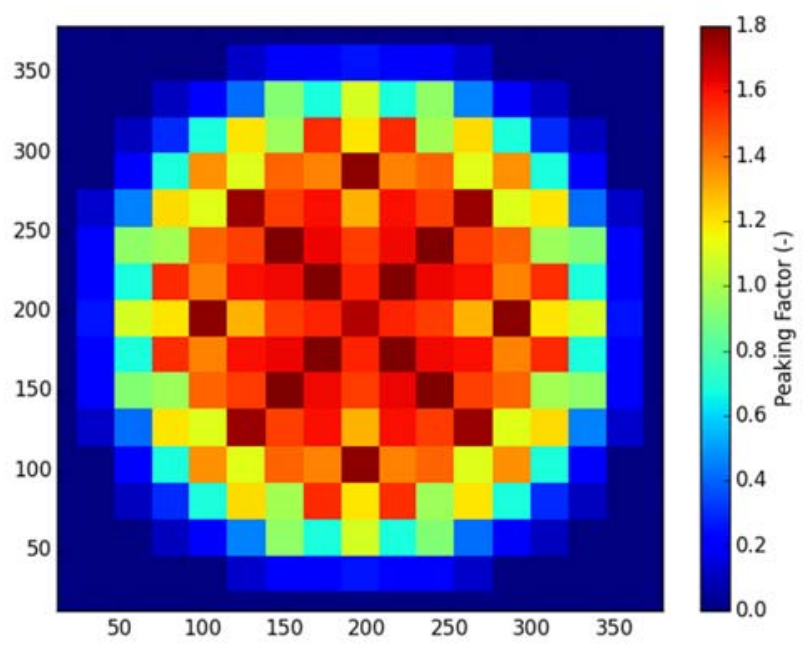

a) radial PF starting from $\mathrm{BOC}$

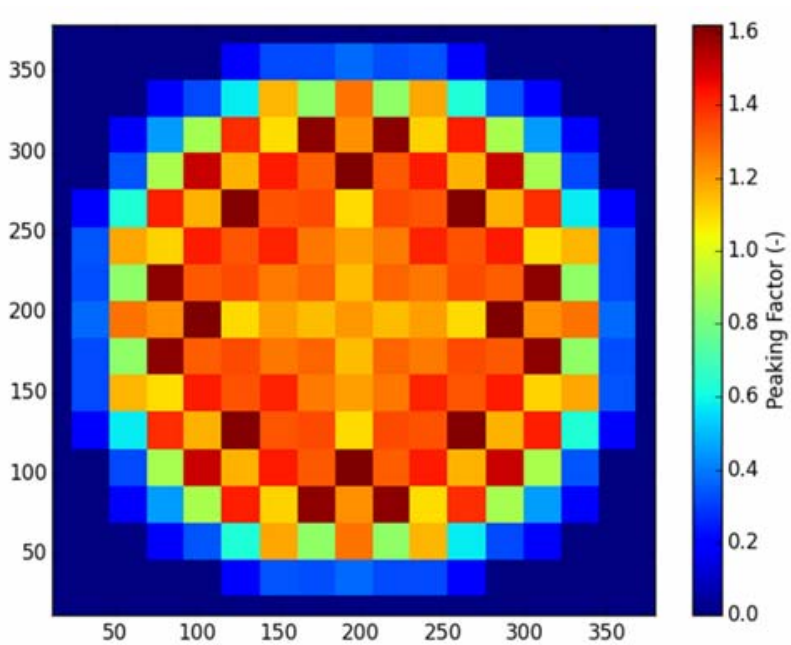

b) radial PF starting from MOC

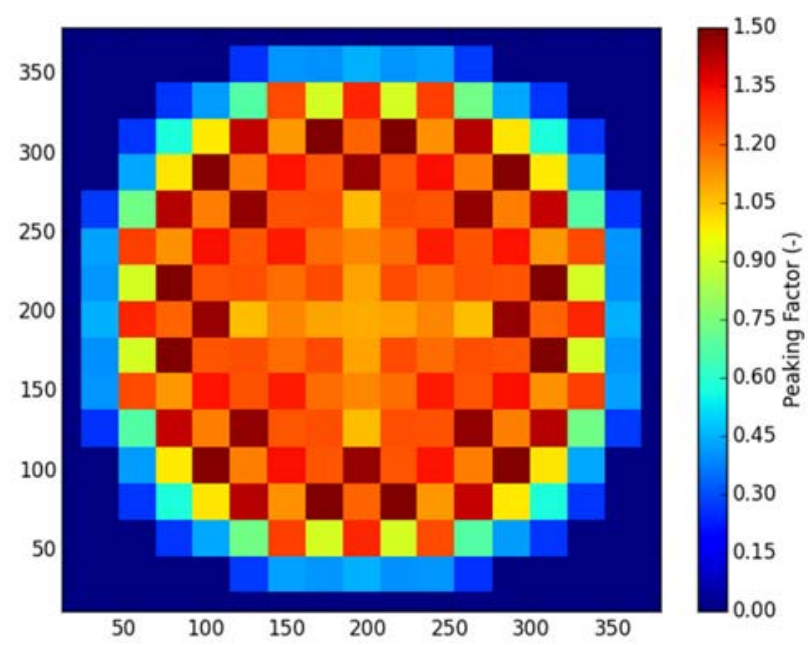

c) radial PF starting from EOC

Figure 14 - Assembly-wise, radial peaking factors after maneuver started from BOC/MOC/EOC (a, b and c) respectively. 


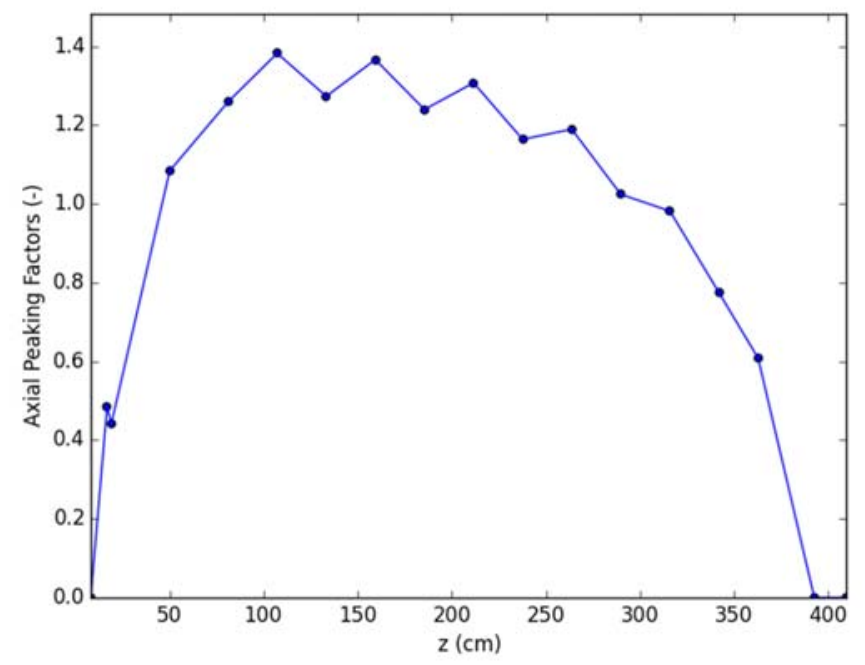

a) axial PF starting from $\mathrm{BOC}$

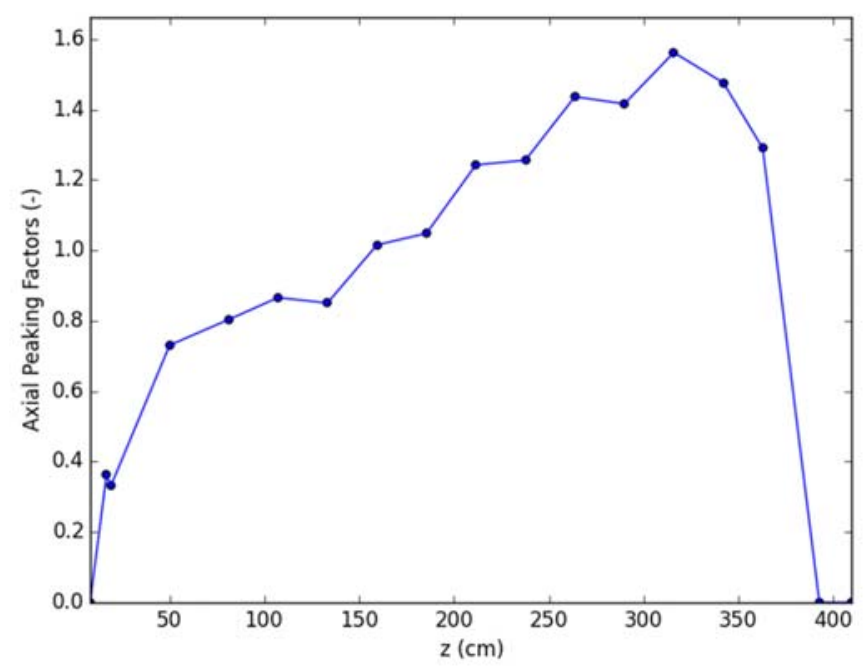

b) axial PF starting from MOC

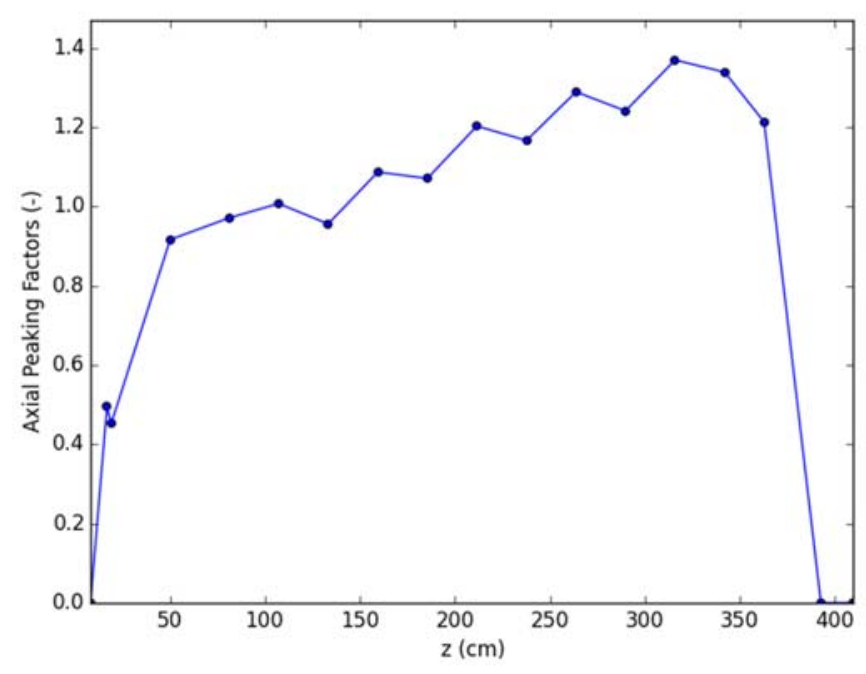

c) axial PF starting from EOC

Figure 15 - Assembly-wise, axial peaking factors after maneuver started from BOC/MOC/EOC (a, b and c) respectively. 
Table 6 - Peaking factors after the maneuver at BOC, MOC and EOC (values in round brackets are the "before maneuver" values).

\begin{tabular}{cccc}
\hline & Radial Peaking Factors & Axial Peaking Factors & Total Peaking Factors \\
\hline BOC & $1.80(1.73)$ & $1.40(1.39)$ & $2.52(2.40)$ \\
MOC & $1.60(1.62)$ & $1.57(1.30)$ & $2.51(2.10)$ \\
EOC & $1.50(1.50)$ & $1.39(1.27)$ & $2.08(1.90)$ \\
\hline
\end{tabular}

Table 6 shows a summary of the radial and axial power peaking factors before and after the maneuver. Considering the approximation taken for the neutron cross sections and the thermal conductivity degradation model, the evolution of the peaking factors is as expected as function of the burnup. In addition, the total peaking factors increased after the maneuver.The largest changes are findable in the axial peaking factors, being the control rods (the different banks) not fully inserted.

As mentioned there were same issues on cross sections for equilibrium cycle reloading pattern, but the approach and results justify why generally this kind of analyses is performed after a maneuver.

\section{LOCA analysis}

At the end of the maneuver, the LOCA analysis is initiated, having as boundary conditions the current status of the plant, as burn-up, power shape, etc. It was not showed but it is easy to understand that on the burn-up side there were not any significant changes between the begin and the end of the maneuver, since the maneuver performed had been finished in only 18 hours. The maneuver has been performed for all these points choosing for the initiation of the LOCA analysis the worst condition, the point in time with the maximum skewed power shape and at the same time an high power.

As it can be inferred, the power shape changed consistently for the presence of the discontinuities represented by the control rods but could be better when the homogenized cross section libraries will be recomputed, considering also the real presence of $\mathrm{Ag}-\mathrm{In}-\mathrm{Cd}$ control rods.

The RELAP5-3D plant model of a four loop pressurized water reactor designed by Westinghouse has been used (INL, 2012b). The model includes the primary and secondary systems, the main steam and feed systems. Also it includes primary and secondary power operated relief valves (PORV) and safety 
valves. The ECCS is included in the primary side model, and the auxiliary feedwater system is modeled in the secondary side modeling. The substantial difference with the original model is in the 6 core channels.

The assemblies have been grouped together taking into account their burnup history: three hot channels has been chosen respectively one with fresh fuel, one with once burnt fuel and one with twice burnt fuel. The others three channels represent the others assemblies with fresh fuel, one burnt fuel and twice burnt fuel respectively group together. Therefore, each group of assemblies with the same burnup history was built in two flow channels, one average channel and one hot channel (Fig. 16).

Since no fuel performance code has been used in this initial methodological assessment, the model of the Heat Structures representing the fuel rods (for the three batches) is invariant with respect the burnup history. This aspect will be addressed in the next stage of the project.

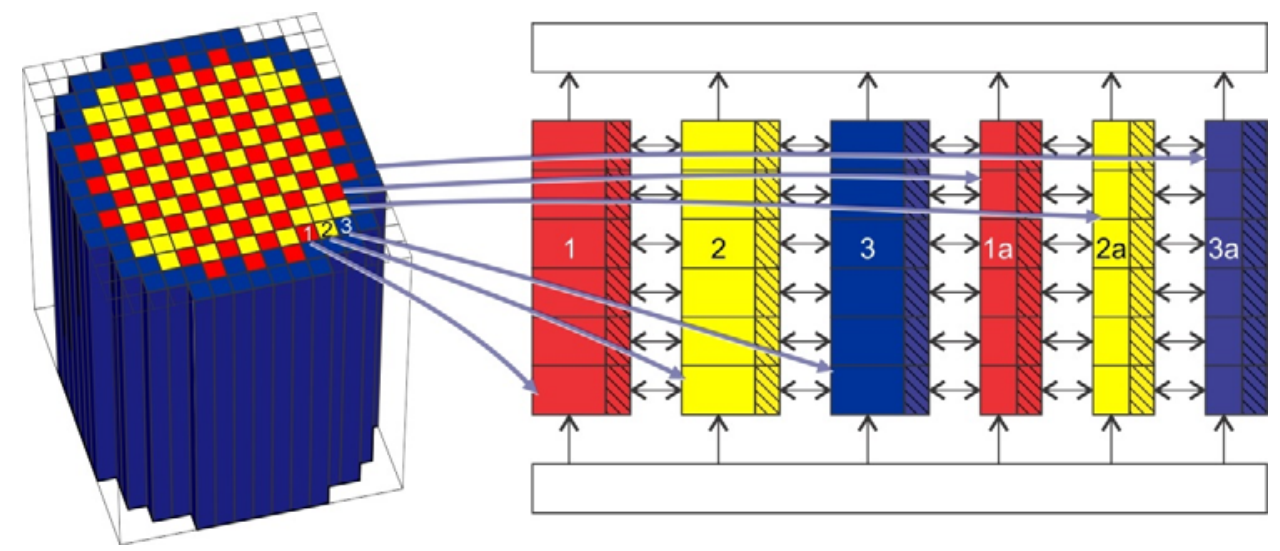

Figure 16 - Illustration of assembly grouping and homogenization in RELAP5-3D calculations

The LOCA analysis begins at the conditions after the maneuver. The study has been conducted on a Large Break LOCA (LBLOCA) (Szilard et al., 2015). The three hot channels were not the same for each point of the analysis. With the burn-up data and the power after maneuver, the PCT (Fig. 17) and the ECR (Fig. 18) evolutions during the transient has been evaluated. 


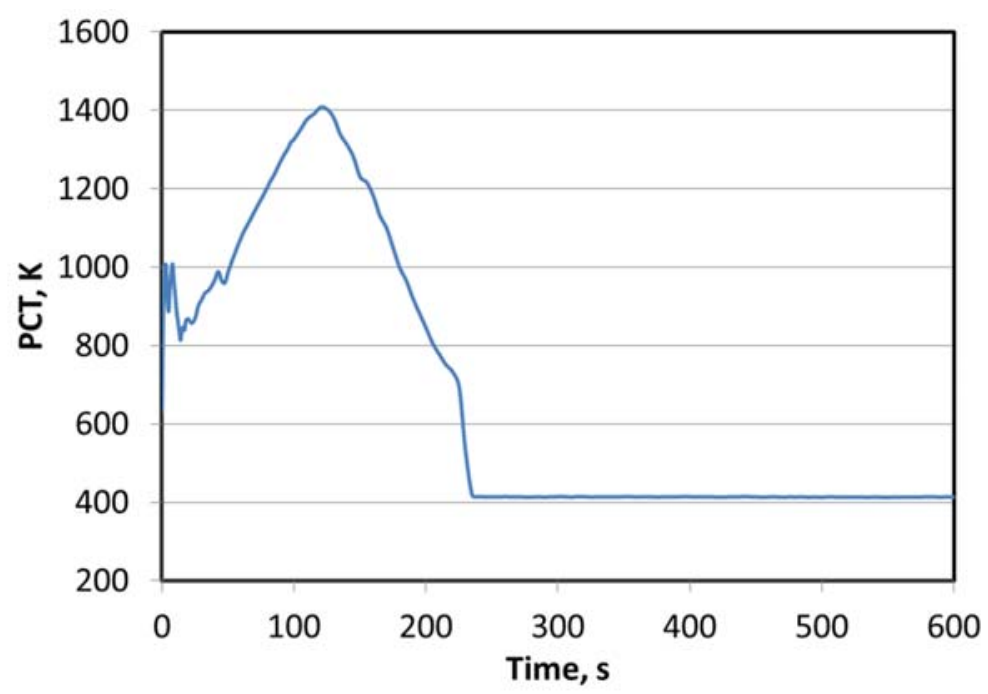

Figure 17 - PCT evolution during LBLOCA transients for 300 days cycle exposure point (Szilard et al., 2015)

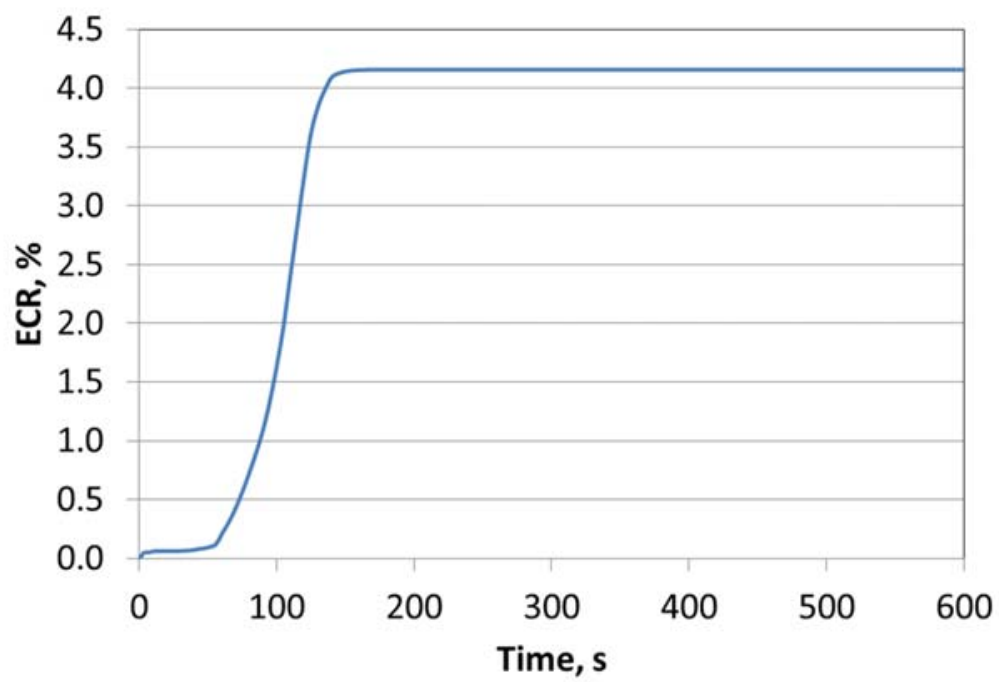

Figure 18 - ECR evolution during LBLOCA transients for 300 days cycle exposure point (Szilard et al., 2015)

The 8 points chosen for the LBLOCA calculations cover the entire range of the cycle length. The selected exposure points are at the beginning of cycle (BOC), 50 days, 100 days, 200 days, 300 days, 400 days, 500 days and end of cycle (EOC). The 8 points per the three hot channels provide 24 PCT (Fig. 19) and ECR values versus hydrogen contents (Fig. 20). 


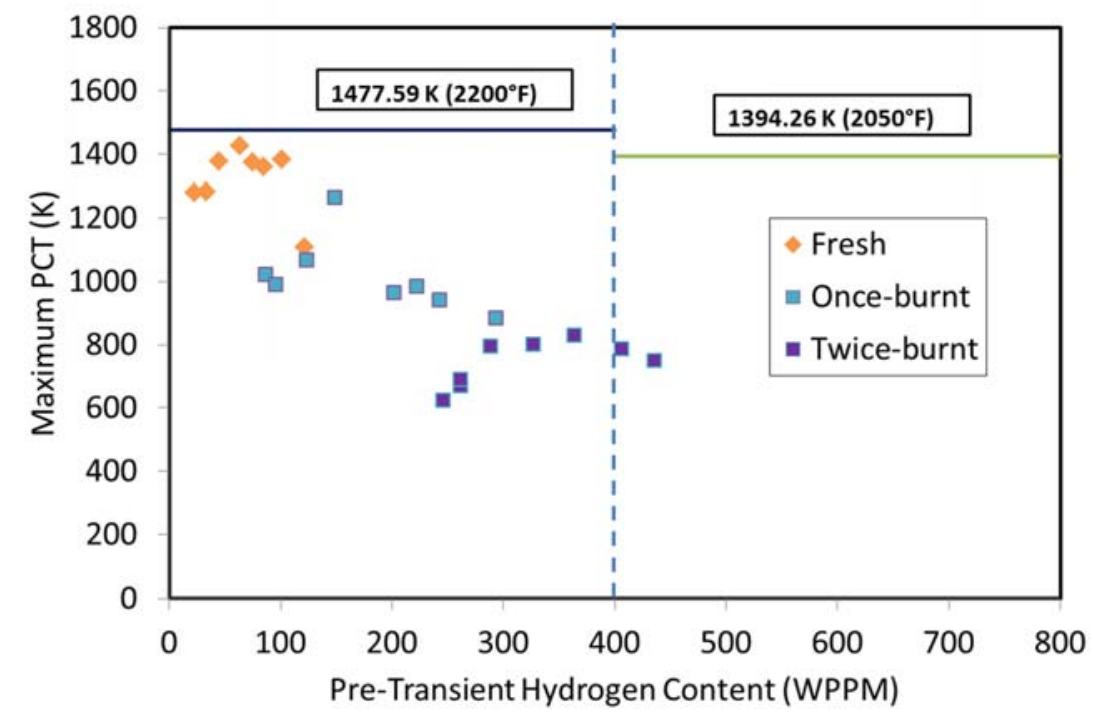

Figure 19 - PCT distribution during LBLOCA transients (Szilard et al., 2015)

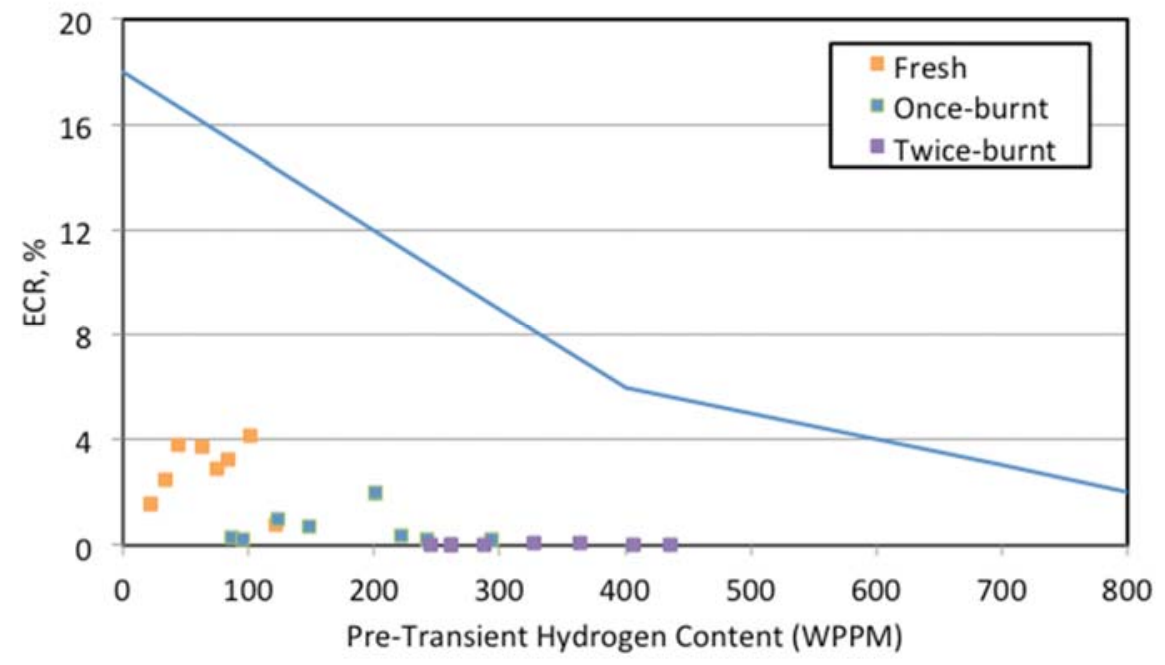

Figure 20 - PCT distribution during LBLOCA transients (Szilard et al., 2015)

The 24 points obtained comply with the CFR 50.46c proposed ECR and PCT limits, validating the ECR and PCT limits as function of the cladding hydrogen pickup ratio before the LOCA accident. As previously discussed, no epistemic and aleatory uncertainties have been considered in the results here presented. The UQ process has been performed and details can be found in Szilard et al., 2015. 
As already mentioned, a Thermal Conductivity Degradation model, as function of burnup, has not been used in this proof of concept analysis. Indeed, based on the equilibrium fuel pattern used for this analysis, the maximum PCTs would happen in the once-burnt fuel assemblies. This approximation determines that future results for ECR and Hydrogen content will be different from the ones here presented. These differences do not reduce the validity of this initial methodology assessment, since the scope of this paper is to present the approach without performing a full "reference" analysis in terms of results.

\section{Conclusions}

The aim of this study is to lay out a roadmap to show the application of a new methodology for the analysis of a wide spectrum of fuel rod initial burnup states, to demonstrate compliance in the design phase with the new Emergency Core Cooling System acceptance criteria, which include the effects of higher burnup on cladding performance, as well as to address other technical issues.

A preliminary application of the methodology, addressing the thermal-hydraulics and reactor physics aspects, has been presented and, despite some adopted simplifications, concerning mainly the fuel performance parameters calculation, the capabilities of the methodology has been demonstrated.

As it can be inferred from the paper, a step-by-step approach has been employed for the demo analysis here presented:

- Core Design for reaching the equilibrium cycle: multi-cycle depletion evolution with T-H feedbacks, boron concentration search (criticality) and fuel shuffling, using the coupled suite PHISICS/RELAP5-3D. This preliminary step has been needed to identify the reference condition (fuel composition and power shape) for the equilibrium cycle (10th), that has been considered as the reference cycle during which the LOCA scenario is initiated;

- Based on the 10th cycle conditions (EOC), another analysis has been initiated to simulate the 11th cycle. During the 11th cycle, multiple points (in time) have been selected to initiate a Load-following transient (that brought to a Xenon transient). The NPP conditions at the selected 8 points in time (BOC, 50, 100, 200, 300, 400, 500 days, EOC) have been used as initial conditions for the Load-following analysis. As already pointed out, the transition between the depletion evolution (cycle 11) and the load-following has been performed automatically using the "multi-deck" capability of the couple suite PHISICS/RELAP5-3D; 
- At the end of the load-following, for each of the 8 points, the reactor conditions (burn-up, power shape, etc.) have been used to initiate a new steady state $\mathrm{TH}$ analysis (no neutronic), to perform the transition from the 1-core channel/assembly model (RELAP5-3D), used in step 1 and 2 , to the 6 core channel model used for the LOCA analysis;

- The LOCA analyses have been finally performed.

The next step of the study will automatize the process. In the present study, in particular performing the $3^{\text {rd }}$ step, some work was done "by hand" as the migration from a 1-core channel/assembly to a 6core channel model, the individuation of the hottest channel and the calculation of fuel performance quantities using empirical correlations.

The current idea is to modify the LOCA model in order to embed the 1-core channel/assembly TH nodalization used in the previous steps and to couple FRAPCON with the suite PHISICS/RELAP5-3D in order to take also in account the mechanical stresses, strains, material property degradation, etc. When this is done, RAVEN will be able to drive the multi-physics analysis in a "once-through" approach, from the simulation of the equilibrium cycle with load-following to the LOCA analysis itself, sampling all the uncertain parameters, including the timing, during the cycle, of the begin of the LOCA scenario.

\section{ACRONYMS}

BEAVRS

BEPU

BOC, MOC, EOC Beginning, Middle, End Of Cycle

CFR Code of Federal Regulation

ECCS Emergency Core Cooling System

ECR Equivalent Cladding Reacted

FRAPCON Code for the calculation of steady-state behavior of oxide fuel rods 


$\begin{array}{ll}\text { FRAPTRAN } & \text { Code for the calculation of transient behavior of oxide fuel rods } \\ \text { INL } & \text { Idaho National Laboratory } \\ \text { LOCA } & \text { Loss Of Coolant Accident } \\ \text { LBLOCA } & \text { Large Break LOCA } \\ \text { MOL } & \text { Maximum Local Oxidation } \\ \text { NPP } & \text { Nuclear Power Plant } \\ \text { NRC } & \text { U.S. Nuclear Regulatory Commission } \\ \text { NUREG } & \text { Nuclear Regulatory Report } \\ \text { PCT } & \text { Peak Cladding Temperature } \\ \text { RHISICS } & \text { Pegulatory Guide } \\ \text { RELAPE } & \text { Pressurized Water Reactor } \\ \text { POR } & \text { Power Operated Relief Valve } \\ & \end{array}$




\section{References}

Alfonsi, A., Rabiti, C., Epiney, A.S., Wang, Y., Cogliati, J., 2012, Phisics toolkit: Multi-reactor transmutation analysis utility - MRTAU, International Conference on the Physics of Reactors, PHYSOR 2012: Advances in Reactor Physics, 3, 2181-2195

Alfonsi A., Rabiti C., Mandelli D., Cogliati J., Kinoshita, R.A., 2013a, Raven as a tool for dynamic probabilistic risk assessment: Software overview, International Conference on Mathematics and Computational Methods Applied to Nuclear Science and Engineering, M\&C 2013, 2, 1247-1261

Alfonsi, A., Rabiti, C., Mandelli, D., Cogliati, J.J., Kinoshita, R.A., Naviglio, A., 2013b, Dynamic Event Tree analysis through RAVEN, International Topical Meeting on Probabilistic Safety Assessment and Analysis 2013, PSA 2013, 3, 1697-1709

Alfonsi A., Rabiti C., Mandelli D., Cogliati J., and Kinoshita R., 2014, RAVEN: Development of the adaptive dynamic event tree approach, Tech. Rep. INL/MIS-14-33246, Idaho National Laboratory

Borchard R. and Johnson M., 2013, 10 CFR 50.46c Rulemaking: Request to Defer Draft Guidance and Extension Request for Final Rule and Final Guidance, U.S. Nuclear Regulatory Commission, Washington, DC

Cathcart J. V., Pawel R. E., McKee R. A., Druscel R. E., Yurek G. J., Cambell J. J. and Jury S. H., 1977, Zirconium Metal-Water Oxidation Kinetics IV. Reaction Rate Studies, ORNL/NUREG-17.

Horelik N., Herman B., Forget B., Smith K., Benchmark for Evaluation And Validation for Reactor Simulations (BEAVRS) v1.01, 2013, Proc. Int. Conf. Mathematics and Computational Methods Applied to Nuc. Sci. \& Eng., Sun Valley, Idaho

INL, 2012a, RELAP5-3D C Code Manual Volume I: Code Structure, System Models, and Solution Methods, INEEL-EXT-98-00834, Rev. 4.

INL, 2012b, RELAP5-3D Code Manual Volume V: User's Guidelines, Idaho National Laboratory Report, INEEL-EXT-98-00834, Rev. 4

Leistikow S., Schanz G., 1987, Oxidation kinetics and related phenomena of Zircaloy-4 fuel cladding exposed to high temperature steam and hydrogen-steam mixtures under PWR accident conditions, Nuclear Engineering and Design, 103(1), 65- 84 
Lyon W. F., Jahingir N., Montgomery R.O., Yagnik S., 2004, Capabilities of the FALCON Steady State and Transient Fuel Performance Code, Proceedings of the 2004 International Meeting on LWR Fuel Performance Orlando, Florida, Sept. 19-22, 678-699

Parsons P.D. et al., 1986, The Deformation, Oxidation and Embrittlement of PWR Fuel Cladding in a Loss-of-Coolant Accident: A State-of-the-Art Report, CSNI Report 129

Perrin J.S., 1993, Utility perspective on management of reactor pressure vessel embrittlement, ASTM Special Technical Publication, (1170), 79-86

PWROG, 2011, Letter Report OG-11-143, PWROG 50.46(b) Margin Assessment

Rabiti C., Alfonsi A., Epiney, 2016, New Simulation Schemes and Capabilities for the PHISICS/RELAP5-3D Coupled Suite, Nuclear Science and Engineering, 182(1), 104-118

Szilard R.H. et al., 2015, Industry Application Emergency Core Cooling System Cladding Acceptance Criteria Early Demonstration, INL/EXT-15-36541

U. S. Code of Federal Regulations, 1997, Title 10, Part 50.46, Article b

U.S. NRC, 1989, Regulatory Guide 1.157 - Best-Estimate Calculations of Emergency Core Cooling System Performance.

U.S. NRC, 2005, Regulatory Guide 1.203 - Transient and Accident Analysis Methods

U.S. NRC, 2014a, FRAPCON-3.5: A Computer Code for the Calculation of Steady-State, Thermal Mechanical Behavior of Oxide Fuel Rods for High Burnup, NUREG/CR-7022, PNNL- 19418, Vol. 1 Rev.1

U.S. NRC, 2014b, FRAPTRAN-1.5: A Computer Code for the Transient Analysis of Oxide Fuel Rods, NUREG/CR-7023, PNNL-19400, Vol. 1 Rev.1

US NRC DG-1261, Conducting Periodic Testing for Breakaway Oxidation Behavior US NRC DG-1262, Testing for Postquench Ductility

US NRC DG-1263 (Draft), Establishing analytical limits for zirconium based alloy cladding

Wemple C.A., Gheorghiu H., Stammler R., Villarino E., 2011, The HELIOS-2 Lattice Physics Code, 18th AER Symposium on VVER Reactor Physics and Reactor Safety, 19-23 September 2011, Eger, Hungary 
Wilks S.S., 1941, Determination of Sample Sizes for Setting Tolerance Limits, Annals of Mathematical Statistics, 12(1), 91-96

Zoino A., Alfonsi A., Rabiti C., Giannetti F., Caruso G., 2015, Simulation Tools and Approaches for the Compliance with Performance-Based ECCS Cladding Acceptance Criteria (10 CFR 50.46C), Transactions of the American Nuclear Society, 113, 1191-1195

S. Ryu, K. Um, J. Lee, 2015, Effect of Thermal Conductivity Degradation for High-Burnup Fuel During a Postulated Control Element Assembly Ejection Accident, Nuclear Technology, 189(2), 163 172 